San Jose State University

SJSU ScholarWorks

Master's Theses

Master's Theses and Graduate Research

1990

\title{
Life satisfaction and activity balance satisfaction among individuals who have undergone hospitalization and rehabilitation for cardiac surgery or myocardial infarction
}

Lauri R. Michaels

San Jose State University

Follow this and additional works at: https://scholarworks.sjsu.edu/etd_theses

\section{Recommended Citation}

Michaels, Lauri R., "Life satisfaction and activity balance satisfaction among individuals who have undergone hospitalization and rehabilitation for cardiac surgery or myocardial infarction" (1990). Master's Theses. 3278.

DOI: https://doi.org/10.31979/etd.uekb-9usk

https://scholarworks.sjsu.edu/etd_theses/3278

This Thesis is brought to you for free and open access by the Master's Theses and Graduate Research at SJSU ScholarWorks. It has been accepted for inclusion in Master's Theses by an authorized administrator of SJSU ScholarWorks. For more information, please contact scholarworks@sjsu.edu. 


\section{INFORMATION TO USERS}

The most advanced technology has been used to photograph and reproduce this manuscript from the microfilm master. UMI films the text directly from the original or copy submitted. This, soinie thesis and dissertation copies are in typewriter face, while others may be from any type of computer printer.

The quality of this reproduction is dependent upon the quality of the copy submitted. Broken or indistinct print, colored or poor quality illustrations and photographs, print bleedthrough, substandard margins, and improper alignment can adversely affect reproduction.

In the unlikely event that the author did not send UMI a complete manuscript and there are missing pages, these will be noted. Also, if unauthorized copyright material had to be removed, a note will indicate the deletion.

Oversize materials (e.g., maps, drawings, charts) are reproduced by sectioning the original, beginning at the upper left-hand corner and continuing from left to right in equal sections with small overlaps. Each original is also photographed in one exposure and is included in reduced form at the back of the book.

Photographs included in the original manuscript have been reproduced xerographically in this copy. Higher quality $6 " \times 9$ " black and white photographic prints are available for any photographs or illustrations appearing in this copy for an additional charge. Contact UMI directly to order.

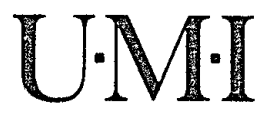

University Microfilms International A Bell \& Howell Information Company 300 North Zeeb Road. Ann Arbor. MI 48106-1346 USA 

Order Number 1340531

Life satisfaction and activity balance satisfaction among individuals who have undergone hospitalization and rehabilitation for cardiac surgery or myocardial infarction

Michaels, Lauri R., M.S.

San Jose State University, 1990

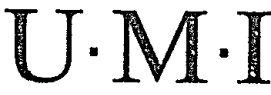





\title{
LIFE SATISFACTION AND ACTIVITY BALANCE SATISEACTION AMONG INDIVIDUALS WHO HAVE UNDERGONE HOSPITALIZATION AND REHABILITATION FOR CARDIAC SURGERY OR MYOCARDIAL INFARCTION
}

\author{
A Thesis Presented to \\ The Faculty of the \\ Department of Occupational Therapy \\ San Jose State University \\ In partial fulfillment \\ of the requirements for the degree \\ Master of Science
}

By

Lauri R. Michaels, OTR May, 1990 
APPROVED FOR THE DEPARTMENT OF OCCUPATIONAL THERAPY $\frac{\text { Stordon Secrton }}{\text { Gordon Burton, Ph.D.. OTR }}$

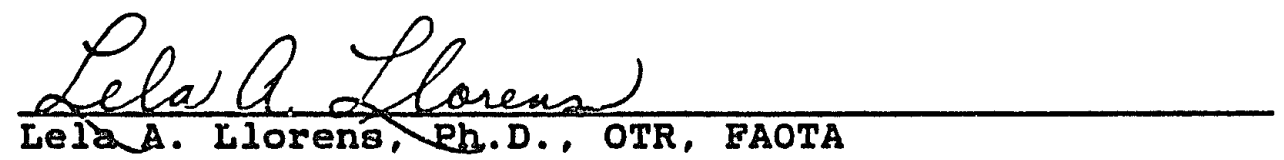
$\frac{\text { Qein }}{\text { Jearstili, fild }}$ APPROVED ROR THE UNIVERSITY

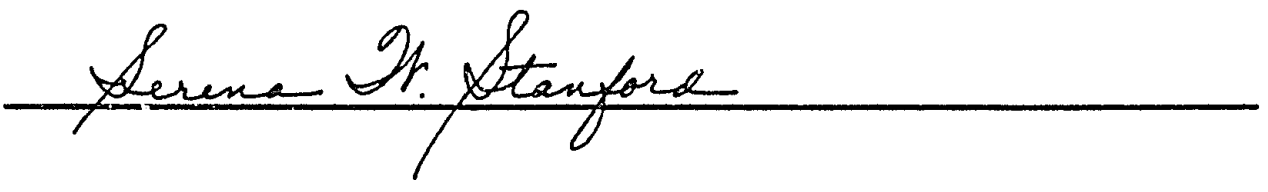




\begin{abstract}
LIFE SATISFACTION AND ACTIVITY BALANCE

SATISFACTION AMONG INDIVIDUALS WHO HAVE UNDERGONE HOSPITALIZATION AND REHABILITATION FOR CARDIAC SURGERY OR MYOCARDIAL INFARCTION
\end{abstract}

BY LAURI R. MICHAELS

The purpose of this study was to determine whether change occurred in life satisfaction and activity balance satisfaction, and whether significant relationships existed between variables of life satisfaction and activity balance satisfaction, among patients who had been hospltalized for myocardial infarctions or cardiac surgery and had participated in a rehabilitation program.

A survey research design was used to identify self-rated lifestyle variables. Questionnaires were completed by 43 participants in the Westside YMCA Cardiac Rehabilitation Program.

Results indicated that there was positive change in reported life satisfaction after hospitalization among those surveyed and varlability in the levels of significance reached. Significant changes were found in lifestyle variables after hospitalization and rehabilitation, including: Decreased work hours, increased strenuous activity, decreased Type A behaviors, improved risk factor management skills, and increased feelings of health. 


\section{ACKNOWLEDGEMENTS}

I would like to express my sincere gratitude to my family for their continuing support and encouragement of my academic pursuits.

I am appreciative to Gordon Burton, Ph.D., OTR, Lela A. Llorens, Ph.D., OTR, FAOTA, and Jean Still, M.S., OTR, as well as the entire faculty of the Department of Occupational Therapy at San Jose State University for their professional expertise and support, which made the completion of this thesis possible.

A special thanks is extended to the staff of the Westside YMCA Cardiac Rehabilitation Program for their cooperation and participation, and especially to the participants in the survey, who provided wonderful verbal and written information about their lives.

The statistical expertise of Leslie Wanek made data analysis and interpretation possible. Her ability to make statistics comprehensible and her excellent organizational skills made the analysis portion of the research an enjoyable and rewarding experience. 
ABSTRACT ........................... i i

ACKNOWLEDGEMENTS . ...................... iv

LIST OF TABLES....................... viii CHAPTER

1. INTRODUCTION....................... 1

Purpose............................ 1

Statement of the Problem................. 1

Objective and Questions................. 4

Definitions........................ 5

Significance of the study................. 10

Assumptions......................... 12

Limitations....................... 13

2. REVIEW OF THE LITERATURE................ 14

Occupational Therapy Theory............... 14

Cardiac Rehabilitation Programs............ 18

Health Risks and Psychosocial Factors......... 22

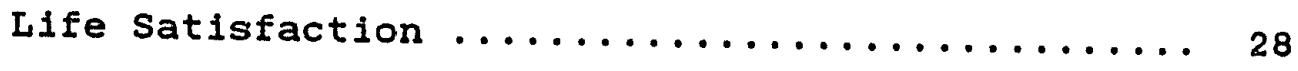

Conclusion. ....................... 34

3. RESEARCH METHODOLOGY.................. 35

Objective and Questions................. 35

Subject selection.................... 37

Research Design..................... 38

Questionnaire Format.................. 38 
Analysis of Data..................... 40

4. RESULTS............................. 44

Hospitalization Data................. 45

Demographic Data.................... 47

Medical Information.................. 49

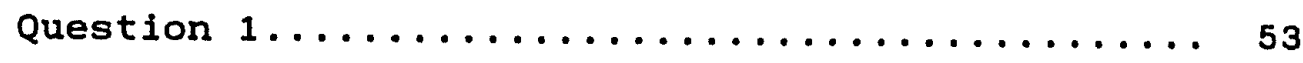

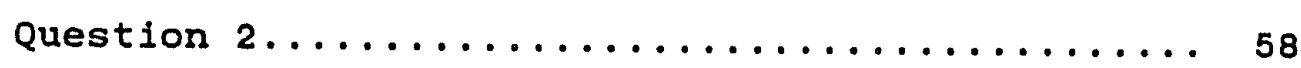

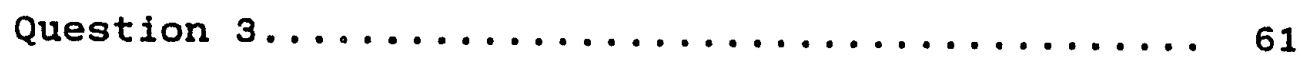

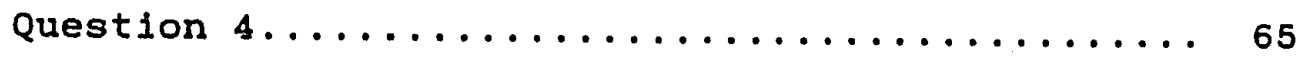

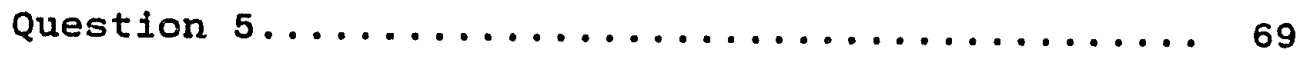

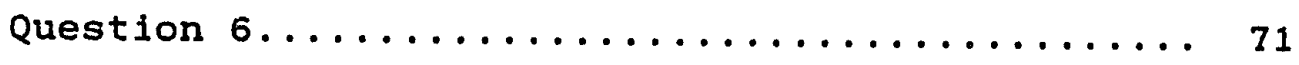

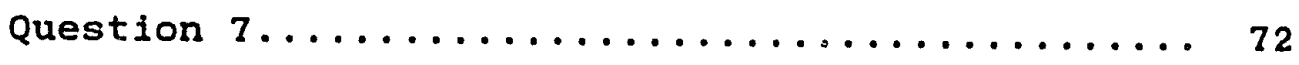

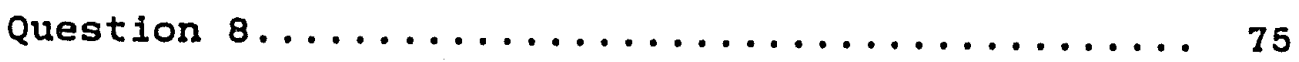

Question $9 \ldots \ldots \ldots \ldots \ldots \ldots \ldots \ldots \ldots \ldots \ldots \ldots \ldots . \ldots \ldots \ldots$

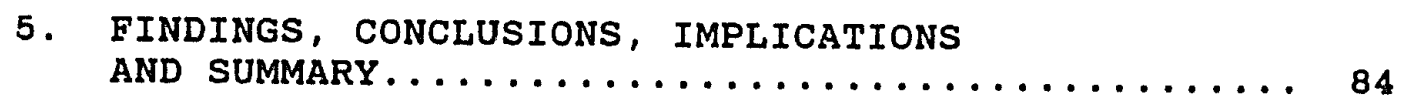

Question $1 \ldots \ldots \ldots \ldots \ldots \ldots \ldots \ldots \ldots \ldots \ldots \ldots . \ldots \ldots \ldots$

Question $2 \ldots \ldots \ldots \ldots \ldots \ldots \ldots \ldots \ldots \ldots \ldots \ldots$

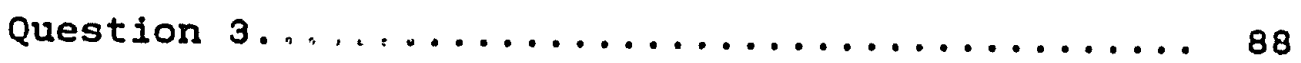

Question $4 \ldots \ldots \ldots \ldots \ldots \ldots \ldots \ldots \ldots \ldots \ldots \ldots \ldots . \ldots \ldots \ldots$

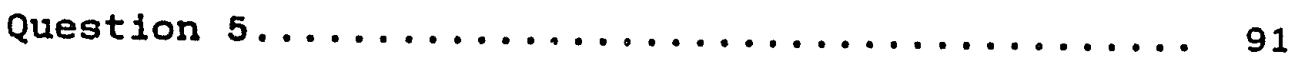

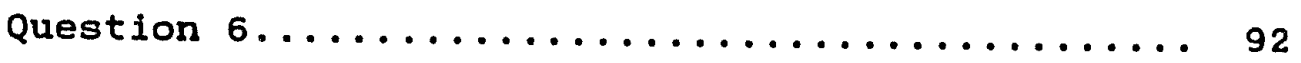

Question $7 \ldots \ldots \ldots \ldots \ldots \ldots \ldots \ldots \ldots \ldots \ldots \ldots . \ldots \ldots \ldots$

Question $8 \ldots \ldots \ldots \ldots \ldots \ldots \ldots \ldots \ldots \ldots \ldots \ldots . \ldots \ldots \ldots$

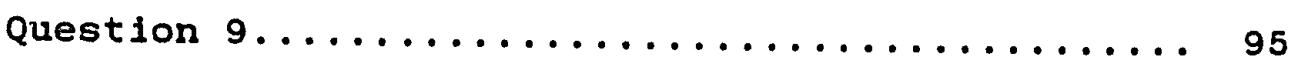

Discussion........................ 96 
Conclusions........................ 98

Implications for Occupational Therapy......... 99

Recommendations for Further Research......... 105

summary ............................ 105

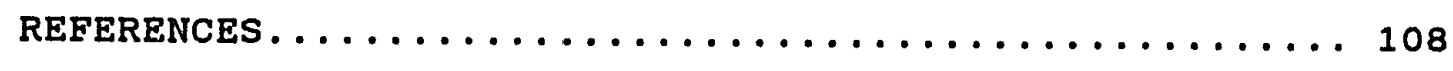

APPENDIX A........................... 117

APPENDIX B........................... 118

$v \pm 1$ 
Page

1. Diagnosis of Respondents at Hospitalization...... 46

2. Coronary Heart Disease-Related Problems........ 51

3. Amount smoked by Respondents............... 52

4. Life Satisfaction - Self-Rated Health......... 55

5. Life Satisfaction - Self-Rated Health Differences........................ 56

6. Perceived Life Satisfaction............... 59

7. Activity Balance Satisfaction............... 60

8. Feelings or Time Constraints.............. 66

9. Type A Behavior - Personality Indicators....... 68

10. Risk Factor Management.................. 70

11. Spearman Correlation Coefficients - Iife

Satisfaction and Activity............... 74

12. Changes in Hours Worked as Grouped by Activity Balance Satisfaction....... 77

13. Changes in Percent of Hours Worked as Grouped by Activity Balance Satisfaction..... 78

14. Changes in Percent of Hours in Non-Strenuous Activity as Grouped by Activity Balance satisfaction................... 79

15. Changes in Percent of Hours in Strenuous Activity as Grouped by Activity

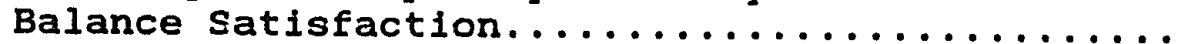


CHAPTER ONE

INTRODUCTION

Purpose

The purpose of this study was to determine:

1) whether change occurred in life satisfaction and activity balance satisfaction among individuals who had undergone hospitalization and rehabilitation for cardiac surgery or myocardial infarction, and 2) whether significant relationships existed between variables of life statisfaction and activity balance satisfaction.

\section{Statement of the Problem}

Coronary heart disease, and subsequent angina pectoris, myocaxdial infarction (MI), sudden death and congestive heart failure, cause nearly 40 percent of all deaths in the United States annually and continue to be a major issue in health car'e today (Carleton \& Lasater, 1983). Nearly two million people survive acute MIs and/or open heart surgery each year, indicating the increasing success rate of recent medical and surgical management of coronary heart disease (Vyden, 1983). As a result of higher survival rates and the contisiuing 
problem of coronary heart disease in society, increasing numbers of professionals have become involved in studying recovery from an acute cardiac event, assessing methods for optimizing post-hospitalization life satisfaction and quality of life, and looking at potential preventive measures.

Cardiac patients form one of the largest populations in health care, as nearly two million people survive heart surgery or acute MI annually (Vyden, 1983). Though the causes of coronary heart disease are not known, several hypotheses have been suggested. Most epidemiologic and experimental evidence supports multiple risk factors, including genetics, cholesterol, cigarette smoking, hypertension and behavioral factors (Multiple Risk Factor Intervention Trial Research Group [MPFITRG]. 1982). Considerable research has been conducted with respect to the physiological, surgical and medical management of coronary heart disease. Less research has attempted to assess the life satisfaction and quality of life of individuals who have sustained coronary heart disease following hospitalization.

As evidence supports multiple risk factors in the causation of coronary heart disease, the patient with coronary disease should ideally benefit from the knowledge of a multidisciplinary team in rehabilitation that includes doctors, nurses, physical and occupational 
therapists, dieticians, vocational counselors, and psychologists; 0.11 of whom can address specific factors. Rehabilitation programs are helpful for patients who must learn to adapt to life-threatening disease and change life-long habits which may have had an impact on the cardiovascular system. Rehabilitation for cardiac patients can also be considered as a secondary preventive measure, as certain lifestyle changes may help to retard the progress of atherosclerosis and subsequent heart problems (Carleton \& Lasater, 1983).

Questions such as: are people able to change life-long habits to improve their overall health; do they alter what has come to be called "Type A" behavior or "coronary-prone" behavior, terms used to indicate high-stress, fast-paced lifestyles (Jenkins, Rosenman \& Zyzanski, 1974); do they improve the balance between work, leisure and self-care in their lives; do they become intrinsically motivated toward the alteration of pathological habits; and do they perceive themselves as having the ability to develop and/or maintain an active, fulfilling life following hospitalization? must be answered in order to determine the impact of occupational therapy and/or rehabilitation on the quality of life of cardiac patients. 


\section{Objective and Questions}

The objective posed for this study was: To determine whether changes in life satisfaction and activity balance satisfaction occurred among patients who had undergone hospitalization and rehabilitation for cardiac surgery or myocardial infarction.

The questions for the study were the following:

1. Did changes occur in life satisfaction, as determined by responses on a Life Satisfaction portion of a Life Satisfaction Questionnaire, pre- and post-hospltalization for myocardial infarction or cardiac surgery?

2. Did changes occur in activity balance satisfaction, as determined by responses on the activity balance satisfaction question in the Daily Activity Information portion of the life satisfaction Questionnaire?

3. Did changes occur in the balance of daily work, leisure and self/family care activities pre- and post-hospitalization, as determined by the Daily Activity Information portion of the Life satisfaction Questionnaire?

4. Were scores on the Personality Information portion of the Life Satisfaction Questionnaire Indicative 
of possible Type A behavior characteristics pre- and post-hospitalization?

5. Did changes occur in risk factor management skills with respect to diet, smoking, exercise, stress and alcohol consumption pre- and post-hospitalization, as indlcated by responses on the Risk Factor Management section of the Iife Satisfaction Questionnaire?

6. Did changes occur in perceived health pre- and post-hospltalization, as indicated by responses on the self-rated health question in the life Satisfaction section of the Life Satisfaction Questionnaire?

7. Does a significant relationship exist between life satisfaction and the variables relating to health and activity?

8. Does a significant relationship exist between activity balance satisfaction and activities of daily living?

9. Does a significant relationship exist between life satisfaction and activity balance satisfaction?

\section{Definitions}

The following definitions were utilized in this study for terms which may be considered to be ambiguous:

1. Activity Balance: The distribution of time allotted to the occupational roles of work, lelsure and 
self/family care in a 24 hour period, as indicated in the "Daily Activity Information" section of the Life Satisfaction Questionnaire.

2. Activity Balance Satisfaction: The satisfaction with the distribution of time allotted to the occupational roles of work, leisure and self/family care, as indicated in the response to question six, "Degree of satisfaction with balance," in the "Dafly Activity Information" section of the Life satisfaction Questionnaire.

\section{Cardiac risk factors: Those factors as} indicated by the MRFITRG (1982) that have been correlated with the incidence of coronary heart disease. These factors are hypertension, diet and nutrition, exercise and smoking. Stress was also included, as correlations have also been made between various behavior and personality traits which indicate stress and coronary heart disease (Philip, Cay, Vetter, \& Stuckey, 1979 and Jenkins, Rosenman, \& Zyzanski, 1974).

4. Cardiac rehabilitation program: outpatient long-term care with the goal of achieving optimal health levels for individuals who have been previously hospitalized for MI or cardiac surgery. Cardiac rehabilitation programs are often divided into four "phases," and the basis of this study was Phase IV, or the maintenance stage, which furthers cardiac 
conditioning, provides education, support, and training toward the goal of secondary prevention and focuses on the development of healthful habits and risk factor management (Comoss, Burke, \& Lasater, 1983).

5. Cardiac Surgery: An operation conducted on the heart. Coronary bypass surgery is the only type of surgery included in this survey. It is indicated as "bypass surgery" on the "Hospitalization/Rehabilitation" section of the questionnaire. This surgery is typically performed as a treatment for cardiac heart disease. When there is insufficient circulation of blood through the arterles supplying the heart, alternative systems for blood flow are provided. This research refers only to first-time hospitalization for coronary bypass surgery and/or MI.

6. Lelsure: Activities performed by individuals primarily for intrinsic satisfaction. These include activities for relaxation, amusement, or self-expression such as sports, drawing, playing the piano, woodworking, or watching television.

7. Life satisfaction: The perception of participants as to the meaningfulness of the activities in which they participate in their daily lives toward the goal of self-actualization. This was assessed by the work, leisure, and self-care balance section and by the life satisfaction section of the questionnaire. 
8. Lifestyle changes: Changes made in daily activities following the stressful life event of hospitalization for MI or cardiac surgery. Changes may include alteration of work, lelsure and self-care balance, as well as the changes made relative to risk factors as recommended by cardiac rehabilitation personnel.

9. Myocardial infarction: Medically, this term refers to the death of cardiac tissue resulting from the sudden stoppage or insufficlency of circulation in the artery supplying the heart (William \& Wilkins Company, 1972). This study utilizes reports of diagnosis of $M I$ by the respondent on the "Hospitalization/Rehabilitation" section of the questionnaire.

10. Occupational therapy frame of reference: The model and/or premises on which occupational therapists base evaluation and treatment. It includes the capacity of the individual, throughout the life span, to perform with satisfaction to self and others those tasks and roles essential to productive living and to the mastery of self and the environment (American Occupational Therapy Association, 1972). Occupational roles and behaviors are often assessed through the occupational performance model of the balance of work, lelsure, and self-care. 


\section{Participants: Those individuals who were} hospitalized for MI or cardlac surgery at least six months previous to completion of the questionnaire. Participants were volunteers who were participating in an outpatient cardiac rehabilitation program at the time that the data were collected, or who participated for at least three months following discharge from the hospital.

12. Percelved health: The report by the paxticipant as to his/her own health status, regardless of medical determinants such as blood pressure or serum cholesterol levels. Perceived health data were obtained from the "Self-rated health" section of the Life Satisfaction Questionnaire.

13. Post-hospitalization: At least six months after the first hospitalization for cardiac problems, and after such time as the Individual has had sufficient opportunity to adapt to a daily routine following hospitalization.

14. Pre-hospitalization: At least six months prior to first hospitalization for cardiac problems and/or prior to the onset of acute symptoms.

15. Risk factor management skills: The ability to change or manage behaviors which have been correlated with the incidence of coronary heart disease by the MRFITRG (1982). This includes maintaining a proper diet, incorporating exercise into one's lifestyle, not smoking, 
not consuming excessive amounts of alcoholic beverages, and reducing stress levels.

16. Self/fainily care: Tasks or responsibllities to oneself or family which satisfy the Individual's basic daily needs, such as eating, dressing or brushing one's teeth.

17. Work: Work includes paid Jobs, as well as unpaid tasks, such as housework and volunteer activities. This study utilized data obtained in the "hours worked" and "productive hours" sections of the questionnaire.

\section{Significance of the study}

Why is it important to assess life satisfaction . among Individuals who have undergone cardiac rehabilitation? The significance of this study occurs on three levels: 1) the personal patient level; 2) the rehabilitation program planning level; and 3) the level of the profession of occupational therapy.

On a personal level, patients involved with outpatient cardiac rehabilitation are in the process of learning how to adapt to life with cardiovascular disease. King (1987) stated that "Individual adaptation refers to adjustments made by the individual that primarlly enhance personal rather than species survival, 
and secondarily contribute to actualization of personal potential" (p. 431). Llorens (1983) expressed the idea that occupational therapy objectives for these clients "are concerned first with the client as an environment that needs to gain or regain integrity in order to function adaptively within the external sociocultural and person-made environments" (p.32). This study focused on identifying particular issues in patients' lives that need to be addressed from their perspectives in order to further their adaptation and integrity.

The second area of significance refers to the rehabilitation program planning level. In order to study the impact that rehabilitation programs have on patients with respect to $x$ isk factor management, lifestyle changes need to be analyzed. In order to further the value and benefits of already existing cardiac rehabllitation programs, studies must be conducted to assess the needs that exist and the programs that are perceived to be particularly beneficial by the patient population. As motivation to change is an important aspect of outpatient cardiac rehabilitation, patient input is essential to determine the factors that motivate people in these situations. If particular habits are found to be more difficult to change than others, or if intrinsic motivation is found to influence abilities to change habits and perception of health, then rehabilitation 
programs can improve their services by incorporating varlous methods aimed at these 1ssues, and increase the possibility of successful cardiac rehabilitation. Program planning could then also become more individualized to suit the needs of patients and groups more precisely.

Thirdly, from an occupational therapy perspective, this study contributes to the scant body of research available on life satisfaction following cardiac rehabilitation. The occupational therapy frame of reference focusing on the occupational performance components of work, leisure, and self/family care is considered to be a viable basis for intervention in rehabilitation, as well as for disease prevention programs. This research will contribute to the body of knowledge regarding the role of rehabilitation and performance in the occupational performance components.

Assumptions

The following assumptions were made while undertaking this research:

1. The event of hospitalization and rehabilitation for cardiac surgery or MI is a stressful iffe event.

2. The events of hospitalization and rehabliftation for the cardiac patient have an influence on the 
individual's lifestyle.

3. The subjects who completed the questionnaire did so to the best of their abilities.

\section{Limitations}

Though the results allowed for inferences to be made with respect to answering the questions in this study, some limitations did exist.

The study used a volunteer research sample. The data collection was by means of a questionnaire which required self-reporting of the data, which is also considered a limitation. Part of the data collected was retrospective in nature, and thus the independent variables of interest were not actively manipulated (Polit \& Hungler, 1383). Survey research is limited in that survey data do not permit the researcher to draw conclusions of cause and effect. Reliablitty and validity tests of the questionnaire were not conducted. It is possible, also, that the subjects may have misunderstood or misinterpreted items on the questionnaire. The research population was limited to those individuals in a long-term cardiac progam, which provided a small sample. 


\section{REVIEW OF THE LITERATURE}

The study of the quality of life and life satisfaction of cardiac patients has increasingly become the focus of research within the medical and psychiatric literature. There are four major areas of literature that pertain to this study: occupational therapy theory, cardiac rehabilitation, health risk factors and psychosocial factors relating to cardiac disease, and life satisfaction. Research within each of these areas that relate to life satisfaction and the cardiac patient will be discussed.

\section{Occupational Therapy Theory}

Though little has been written with respect to the occupational therapist's role in cardiac rehabilitation, a great deal has been published regarding adapting lifestyles and behaviors to chronic illness. Various frames of reference are pertinent to the problem which is the topic of this study, including occupational performance, occupational behavior, systems interaction, and environmental development. 
Adolph Meyer (1922) was one of the first individuals to emphasize the importance of performance and the use of one's time with respect to adapting to 11 lness. He focused on the balance between the physical and psychological aspects of man, stating that humans should be considered to be integrated units. He felt that what one does with his/her day--performance--is the fundamental determination of personality (Meyer, 1922). The philosophy of Meyer was furthered by the work of Reilly (1962), who wrote that through involvement in purposeful activities, individuals can remediate dysfunction and thereby influence the state of their own health. She stated that occupational therapy's base is founded on the balance between work, leisure, self-care and sleep in one's daily life (Reilly, 1962). These are considered to be occupational behaviors that underly social roles.

An important component of an individual's occupational functioning is the meaningfulness of his/her activities. Occupational behavior theory includes concern for the type, amount, and meaningfulness of one's activities (Gregory, 1983). Reilly (1978) emphasized the importance of self esteem, social roles, and intrinsic motivation on human well belng and adaptation. Occupational roles and intrinsic motivation as linked to IIfe satisfaction were the background for Yerxa and 
Baum's work (1985). They utilized the concept of internal versus external locus of control, as well as daily activities and perceived happiness when assessing life satisfaction (Yerxa \& Baum, 1985).

Occupational behavior was organized in a systems format by Kielhofner and Burke (1980). They postulated that human activity should be organized for study on a multidimensional continuum of input, adaptation or throughput, output, and feedback (Kielhofner \& Burke, 1980). Individual's actions with respect to their environments form the basis for this theory. Kielhofner also applied the use of this model to clinical practice, emphasizing that therapy should take into account the patient's interests, valued goals, and personal causation with regard to this environment (Kielhofner \& Burke, p. 581).

King (1978) also focused on the importance of adaptive responses to one's environment. She believed that life is a continuum of adaptation and how well one adapts influences life satisfaction. She stated that goal-directed activities are positive in allowing patients to display adaptive responses to stress. King asserted that physical change (including cardiac illness) is considered to be a stressor, and the individual must learn to adapt to such stressors in order to improve his/her sense of well being. 
Llorens (1984) described the role of occupational therapy in the process of changing balance from dysfunction to function. She stated that occupation can serve the purpose of facilitating change in the individual environment. Occupational therapy can be used to intervene in the input, integration, output and feedback cycle to bring about change and balance.

Llorens (1984) also emphasized the importance of occupational therapy in the commitment to habilitation and rehabilitation and the application toward improving the quality of life beyond the medical role of cilient care. The American Occupational Therapy Association (1979) proposed that the role of occupational therapy should include the promotion of health and the prevention of disabilities, including secondary prevention, such as cardiac risk factor management.

Pedretti and Pasquinelli (1990) discussed the importance of a frame of reference as a unifying conceptual system for guiding the practice of occupational therapy. They proposed that "occupational performance" is a frame of reference which can serve as this system. Occupational performance is defined as "the individual's ability to accomplish the tasks required by his or her role and related to his or her developmental stage... Occupational performance includes self-care, work and play/leisure time performance" (Pedretti \& 


\begin{abstract}
Pasquinelli, 1990, p. 17)
The holistic perspective of occupational therapy, then, with its emphasis on the role of activities, behaviors, and social roles in the determination of human well being and function, is ideally suited to the study of life satisfaction and health management for a cardiac outpatient population.
\end{abstract}

\title{
Cardiac Rehabilitation Programs
}

Rehabilitation programs for cardiac patients are an increasingly popular form of medical intervention. A study by Goldman and Cook (1984) indicated that in recent years there has been a decline in mortality rates attributable to ischemic heart disease. Various medical interventions were analyzed and based on vital statistics and other quantitative data. They determined that many factors impacted on the decline in mortality rates. Both medical interventions and lifestyle changes such as weight reduction and smoking cessation had beneficial implications. Potential benefits in terms of lives saved was estimated for the various factors. It was determined that potential interactions and relationships must be considered with respect to relative costs in order to further health care planning in the future (Goldman \& 
Cook, 1984).

The specific interventions of a four-phased cardiac rehablitation program has been outlined by winslow (1982). Phase 1 involves treatment in the hospital, Phase 2 occurs immediately post-hospitalization, Phase 3 includes exercise training and education, and Phase 4 is maintenance and assessment of carryover of training. Goals outlined include decreasing mortality rates through changing exercise patterns and coronary risk factors (Winslow, 1982). He determined that costs were easily justifiable in terms of the benefits to patients and society.

A study was conducted in singapore regarding the benefits of such a comprehensive cardiac rehabilitation program (Sabapathy, 1981). Thirty patients were taken into a pilot cardiac rehabilitation program at singapore General Hospital for over a period of one year. Exercise training was undertaken, exercises were conducted and angina and irregular heart rhythms were noted. No cardiac arrest occurred during the course of the study. The study showed an exercise program in a ceneral hospital to be safe and feasible. In an associated study of patient reactions, the program was determined to be beneficial physically, emotionally, socially, psychologically and spiritually (Sabapathy, 1981). 
Along with exercise, incorporation of psychosocial and educational components has been found to be successful in cardiac rehabilitation programs (Hackett \& Cassem, 1982 and Rahe, Scalz1, \& Shine, 1975). Common misconceptions following heart surgery or MI were decreased or eliminated through education and supervised successful activities within the course of rehabilitation.

Many studies have been conducted to assess the success of medical regimens with respect to cardiac patients. Few, however, have analyzed the rehabilitation program as a whole. A study by wilson-Barnett (1981) indicated that rehabilitation within the hospital settings vary widely, and patients are often sent home with a minimum of discharge planning. other studies have been more encouraging with respect to the improvement of the functional state of the patients following cardiac rehabilitation (Fletcher, 1982 and Philip, 1982). Though some aspects of recovery such as social factors are difficult to assess, individuals who have undergone rehabilitation have been shown to have a significantly greater exercise tolerance and a higher probability of being employed than non-participants. The effects of rehabilitation on the psychologic functioning of patients have also been encouraging. Erdman and Duivenvoorden 
(1983), using a small sample, concluded that outpatient rehabilitation lead to a diminished sense of social inadequacy, feelings of self-esteem were increased and anxiety was decreased. However, they found that rehabilitation did not have an influence on work resumption, as had been indicated by the Fletcher study. They found that smoking and exercise behaviors were improved as a result of rehabilitation.

According to Miller, Johnson, Garrett, Wickoff and McMahon (1982), rehabjiltation programs which are designed to assist the patient in gaining a sense of control over the medical regimen should increase compliance. Counseling on risk factors, diet, emotional factors, hazards, daily physical activities, exercise, and vocational factors have been considered to be important in a well balanced cardiac rehabilitation program (Semmler \& Semmler, 1974). Prescribed behaviors of the medical regimen, however, are frequently neglected after the patient's return to the societal role (Miller, et al., 1982).

A holistic biopsychosocial model for education is important in the facilitation of rehabilitation (Egnew \& Jones, 1984). The importance of long-term rehabilitation programs which offer experiential as well as academic learning, and behavior modification techniques along with exercise tolerance training is evident. 
Health Risk and Psychosocial Factors

Many studies have been conducted regarding factors which are thought to contribute to coronary heart disease and accompanying cardiac problems. Most studies assess either behavioral factors which impact on the physiological aspects of the disease and quality of life after onset, or they pertain to psychosocial factors of the disease.

Health risk factors which affect the physiological being have been commonly associated with cardiac disease. In July, 1970 the National Heart and Lung Institute convened a task force on arteriolsclerosis in order to develop a broad long range plan for the study, control, and possible prevention of the disease (MRFITRG, 1982). An outcome of this research was a primary study conducted on 12,866 men to assess mortality rates following intervention. The study was longitudinal and looked at demographic features, plasma cholesterol, weight, previous heart attacks, ischemic response to exercise, blood pressure, and dietary data (MRFITRG, 1982). The study concluded that intervention was beneficial in encouraging risk factor changes. However, beneficial effects on heart disease or total mortality rates were not substantiated (MRFITRG, 1982). The report 
was favorable in strengthening the position that smoking and hypertension have an adverse effect on the heart. High serum cholesterol, as well as high blood pressure and cigarette smoking, has also been positively linked to the recurrence of MI (Kornitzer, 1982). Other risk factors include lack of exercise, and excessive body weight over 20 pounds (Carleton \& Lasater, 1983; Metzner, Carman \& House, 1983; Munga1, 1984 and Reiff, et al., 1967). However, though the epidemiologic evidence is relatively strong for each of these health factors, the clinical evidence from trial interventions remains ambiguous (Carleton \& Lasater, 1983). It is important, then, to emphasize total lifestyle (behavioral patterns which have physiological consequences), rather than risk factors individually, when studying this phenomonon, when developing rehabilitation programs, and when encouraging secondary prevention of coronary heart disease. Browner (1987) emphasizes the importance of assessing the impact of available risk modification programs when planning public health strategies.

Disease results in disruption of normal psychological and social functioning, as well as physiological functioning (Doehrman, 1977). In a study which reviewed the extensive literature on the topic, Doehrman concluded that long-lasting emotional distress, familial problems, and occupational maladjustment were 
observed on a large group of patients and that psychological counseling facilitated rehabilitation. Gundle, Reeves, Tate, Raft, and Mclaurin (1980) also found that despite good physiologic outcomes after coronary artery surgery, patients were functioning poorly psychosocially one to two years after surgery, as evidenced by higher levels of unemployment and sexual impairment. They found that most patients who had suffered angina for long duration also evidenced a damaged self-concept.

Other studies assessing psychosocial outcomes were more positive, however. Two studies from England concluded that the quality of life after cardiac surgery significantly improved as compared to pre-hospitalization (Westaby, Sapsford \& Bentall, 1979 and Ross, et al., 1981). It was also found that quality of life, reflected in avocational and "self-improvement" activity levels, increased significantly following coronary artery surgery (Barboriak, Anderson \& Rimm, 1983, p. 215).

The importance of values clarification on the rehabilitation of cardiac patients from a psychosocial perspective has also been analyzea (Berger, Hopp \& Raettig, 1975). It was concluded that this approach, which emphasized self-chosen goals, was an effective adjunct to treatment for certain patients, but was less effective for those over the age of 60 years. It is 
clear, then, that though psychosocial aspects are evident both before and after diagnosis for coronary heart disease, the effect of this type of treatment in addition to traditional treatment remains inconclusive.

Certain psychosocial behaviors have been considered to have an impact on coronary heart disease. Friedman and Rosenman (1971) have suggested that a personality profile, which they term "Type A," exists and that this profile is associated with coronary heart disease (p. 300). Characteristics associated with Type A behavior include excessive competitive drive and a chronic, continual sense of time urgency, accompanied by the feeling of always having to meet deadlines (Pelletier, 1977). Pelletier has suggested that when this aggressive behavior is generalized rather than channeled, the effects are diffuse on both a psychosocial and neurophysiological level, producing prolonged stress which may. result in heart disease.

An instrument measuring Type A behavior has been developed by Jenkins, Rosenman and Zyzanski (1974). Their study of 2,750 employed men found that the coronary-prone behavior pattern was linked to the pathogenesis of coronary heart disease (Jenkins, Rosenman \& Zyzansk1, 1974). Another study conducted by Byrne (1981) concluded that recent stressful life events preceding MI were significantly correlated with Type A 
behavior patterns regarding an association with cardiac illness. A study from England using the Bortner questionnaire, a test which related well to the Jenkins questionnaire, found, however, that Type A behavior did not predict major ischemic heart disease in British midule-aged men (Johnston, Cook \& Shaper, 1987).

As it is important to determine personality and behavior characteristics as they impact on the development of heart disease, so is it necessary to study potential behavioral changes as secondary prevention. Behavioral traits are important also in the determination of effective rehabilitation planning. Philip, Cay, Vetter and stuckey (1979) concluded that most survivors of MI are more introverted and self-contained than healthy individuals. They felt that this submissiveness and cautiousness may result in slowed response to treatment. They also concluded, which also conflicts with the Type A behavior theory, that the cardiac patients in their study were not more anxious than healthy individuals.

A study by Ruberman, Weinblatt, Goldberg, and Chaudhary (1984) affiliated social isolation with Type A behavior. They found that individuals with education of less than 12 years had higher stress levels and were more socially isolated, and thus were at higher risk for sudden cardiac deaths and total number of deaths than 
better educated individuals. This study was soon refuted on methodology due to the fact that the scale for Type A behavior that was used (not the Jenkins scale) was not tested for reliability or validity (Abbott \& Vogel, $1985)$.

In an extensive study of 1,035 post-infarction patients, Friedman, et al. (1982) found that secondary prevention was most effective when both cardiologic and behavioral counseling that focused on eliminating Type A behaviors was employed. They stated that those individuals who received only the behavioral counseling had a lower rate of nonfatal infarction than those who received only cardiologic counseling. Based on this study, Friedman, et al. (1982) suggested that Type A behavior be included among commonly accepted risk factors for cardiac disease. This study presents evidence for the strong effects that one's behavior and lifestyle can have on the pathogenesis of cardiac disease. 


\section{Life Satisfaction}

The study of life satisfaction has been primarily involved with attempts to define and measure the psychological well being of individuals, usually with respect to aging. There have generally been two perspectives to this issue in the literature (Neugarten, Havighurst \& Tobin, 1961). One focuses on the overt behaviors of the individual and utilizes social criteria of success or competence, thus studying using activities and social participation variables. The other perspective focuses on the individual's internal frame of reference. Here the person's evaluations of his/her present or past life and his/her satisfaction are the variables measured. This perspective assumes that the individual is the most appropriate fudge of happiness, thus minimizing the researcher's value judgements (Neugarten, Havighurst \& Tobin, 1961).

Most studies in the recent literature combine the above perspectives in the formulation of measures and studies of life satisfaction. The Neugarten, et al. (1961) study presented a set of scales for the rating of life satisfaction called the Life Satisfaction Index (L'SI), which was based on data from 177 men and women aged 50 to 90 years. It was found that the scales proved most useful for measuring life satisfaction of 
individuals over age 65. Wood, Wylle and Shaefor (1969) used the ISI scales in a replication study of the instrument using an aged rural population. They correlated two of the scales--the Life Satisfaction Rating (LSR) and the Life Satisfaction Index A (LSI-A). The correlation was found to be approximately equivalent to that of the Neugarten, et al. study (1961), showing the validity and reliability of the scales for this population.

Based on Wood, Wylie, and Shaefor's study, Adams (1969) analyzed the LSI, though he eliminated seven items at the suggestion of the previous researchers. He concluded that the ISI-A provided a fair estimate of life satisfaction for a small town elderly sample, as well as for the urban and rural elderly samples previously tested (Adams, 1969) .

A study was conducted by Lohmann (1977) to further correlate various life satisfaction indices, including those mentioned previously. She found that a high level of correlation among the several measures of life satisfaction, attitude, and morale indeed existed based on data collected from subjects over age 60 . She suggested that this could be interpreted to mean that these various measures are directed toward a common underlying constraint. 
The occupational therapy literature relating to life satisfaction has also primarily focused on the aged. Two studies were conducted based on data collected in nursing homes. They focused on need satisfaction--satisfying of basic needs as defined by Maslow--as a prerequisite to the ultimate goal of self actualization (Tickle, 1980 and Walker \& McCoy, 1959). In these studies both activity involvement and adequacy of environment were taken into account in the judgement of need satisfaction. Another perspective in the occupational therapy literature was the effect of occupational behavior on life satisfaction (Gregory, 1983). Gregory studied the type, amount, and meaningfulness of one's activities in the determination of life satisfaction. He concluded that occupational behavior was a significant factor associated with life satisfaction among retirees. He reported that the performance of purposeful activities was important in the maintenance of high life satisfaction levels among the elderly.

Other populations than the elderly have been studied with respect to life satisfaction, as well. A recent study by Yersa and Baum (1985) was conducted with the assumption that dally activities are related to life satisfaction. They utilized the occupational behavior perspective, which included satisfaction with performance in various daily roles, as well as an assessment of locus 
of control of one's life (Yerxa \& Baum, 1985). Though their sample size was small, they were able to conclude that people with disabilities whom they had studied had life satisfaction and locus of control levels that were comparable to non-disabled individuals. They found that there was no relationship between employment and life satisfaction, but there was a significant relationship between avocational activities and life satisfaction (Yerxa \& Baum, 1985).

Decker and Schulz (1985) studied life satisfaction among individuals who were both elderly and had spinal cord injuries. The Life Satisfaction Index-A scale was used. It was found that this group reported a degree of well being that was only slightly lower than similarly aged non-disabled people. Those who reported a higher degree of life satisfaction were those who judged their health status to be good, viewed their disability more favorably, and reported a greater locus of control (Decker \& Schulz, 1985).

It is important to study health variables as determinants of self-perception, particularly when assessing life satisfaction with respect to specific disabilities. Tornstam (1975), in a study in Sweden, found that the expected relationship between poor health and attitudes found little support in the empirical data. He found that health variables are of different 
levels of importance, with objective health status being influenced by subjective status. Also, health varlables are conditions for some self-perceptions. He concluded that health status and self-perception imply multifaceted interactions and cannot be assessed by implying interaction between only two variables (Tornstam, 1975). Conversely, Palmore and Liukart (1972) found that self-rated health was the predominant variable in an analysis of health, activity, social-psychological, and socio-economic variables thought to influence life satisfaction. This was a longitudinal study of 502 persons aged 45-69 years. The measures were based on various aspects of the above variables, using Cantril ladders (1965) and Likert scale methodology (Palmore \& Liukart, 1972). As with other studies of life satisfaction, activities and locus of control variables were assessed along with health and demographics. They found that self-rated health was the strongest varlable related to life satisfaction with this population sample. Organizational activity, then internal control, were the next most significant variables. As in Yerxa and Baum's study, productive hours, though not necessarlly employment, was also a strong variable related to internal control (Palmore \& Luikart, 1972). Another significant study relating to life satisfaction was conducted by Palmore and Kivett (1977). 
This was a longitudinal analysis of possible changes in Ife satisfaction variables over time. In a sample of 378 subjects aged 46-70 years, no significant changes in mean life satisfaction scores for any age or sex demographic grouping were found. Life satisfaction was assessed using similar measures to the above Palmore and Luikart (1972) study. Findings indicated that life satisfaction was significantly related to initial levels of self-rated health, social activity and sexual enjoyment. This was similar to the findings of the Palmore and Luikart study. Though they were unable to predict changes in life satisfaction over time, the analysis gave support to the theory that it is important to "maintain good health and to remain socially and sexually active" (Palmore \& Kivett, p. 316). One study was found in the literature which related behavior and life satisfaction characteristics to subjects with heart disease (Theorell \& Rahe, 1970). The analysis was conducted on 62 middle aged Swedish male subjects who had survived Initial MIs as compared with 109 men determined to be free of coronary heart disease. It was found that the post-MI subjects worked more overtime hours, received less satisfaction from their jobs and felt greater hostility when slowed down by others. This study assessed and supported the Type A behavior perspective with respect to life satisfaction, 
as opposed to the studies which focused on activities and perception of health and social status as they related to life satisfaction.

Conclusion

It is evident that although some of the research presents conflicting findings, results have been reported that support the proposed relationship between life satisfaction and adaptation to cardiac disease. Further study of cardiac rehabilitation programs, health risk factors-both physiological and psychosocial--related to cardiac disease, and life satisfaction in general is warranted. It is apparent that health risk factors are highly interrelated and no evidence has shown that any individual variable is solely responsible for cardiac disease. Little has besn written as yet relating life satisfaction, activity balance satisfaction and cardiac disease. 
CHAPTER THREE

RESEARCH METHODOLOGY

Objective and Questions

The objective of this study was to determine whether changes in life satisfaction and activity balance satisfaction occurred among individuals who had undergone hospitalization and rehablitation for myocardial infarction or cardiac surgery. The occupational therapy frame of reference was utilized to determine life satisfaction, behavioral, daily activity, and health risk management variables before and after hospitalization.

The questions posed for the study were the following:

1. Did changes occur in life satisfaction, as determined by responses on the Life Satisfaction questionnaire, before and after hospitalization for MI or cardiac surgery?

2. Did changes occur in activity balance satisfaction, as determined by responses to the "activity balance satisfaction" portion of the Life satisfaction Questionnaire, pre- and post-hospitalization for myocardial infarction or cardiac surgery? 
3. Did changes occur in the balance of daily work, lelsure and self/family care activities before and after hospitalization, as determined by the Daily Activity Information portion of the Life Satisfaction Questionnaire?

4. Did changes occur in personality factors, as determined by the Type A behavior section of the questionnaire pre- and post-hospitalization?

5. Did changes occur in risk factors management skills with respect to diet pre- and post-hospitalization and rehabilitation, as indicated by responses on the Risk Factor Management section of the Life Satisfaction Questionnaire?

6.. Did changes occur in perceived health levels pre- and post-hospitalization, as indicated by responses on the self-rated health question in the Life Satisfaction section of the Life Satisfaction Questionnaire?

7. Does a significant relationship exist between life satisfaction and the variables relating to health and activity?

8. Does a significant relationship exist between activity balance satisfaction and activities of daily living? 
9. Does a significant relationship exist between life satisfaction and activity balance satisfaction?

Subject selection

The subjects for this study were selected from a population of patients who participated in an outpatient cardiac rehabilitation program. The subjects had been hospitalized for their first or only cardiac surgery or MI at least six months prior to the completion of the questionnaire. The subjects were limited to those who were able to read and write English and cognitively intact enough to complete the questionnaire, including the parts requiring retrospective data. This was determined by cardiac rehabilitation staff members who obtained such knowledge through clinical observations and/or hospital records.

The sample size of 70 was determined by the numbers of individuals at the Westside YMCA Cardiac Rehabilitation Program who met the above criteria and who volunteered to complete the questionnaire. The sample was selected from only one rehabilitation program. All qualified individuals in that program were included. Since only those subjects who returned the questionnaire were included in the data analysis, the final sample was a volunteer research sample of 48 subjects. 


\section{Research Design}

Survey research methodology was utilized for this study, as the necessary data were obtained through a self-reported questionnaire. Data were obtained on retrospective perceptions of pre- and post-hospitalization status in order to answer the questions which were the basis for this study. The data for the information on Question 1, relating to Life Satisfaction were analyzed independently, and in relation to the variables related to it. For the following: Daily activities, personality and Type A behaviors, life satisfaction, and health risk factors. The relationships between the variables of daily activities, personality and Type A behaviors, life satisfaction and health $r$ isk factors were assessed.

\section{Questionnaire Format}

The questionnaire packet included a cover letter that explained the basis of the research and a short questionnaire (Appendices $A$ and $B$. ) The first section of the questionnaire is entitled "General Information" and covers demographic variables such as age, sex, education level, and employment status. The second section is 
called "Medical Information" and asks for data on hospitalization, cardiac diagnostic variables and smoking history. Section $\mathrm{C}$ is entitled "Family Medical History." which contains a chart format for medical data of family members. The next section, "Daily Activity Information" covers the variables of work, leisure, and self/family care in terms of hours in a typical day. This section was based on a section of a questionnaire by Mungai (1984), which covered activities of daily living and perceived health of a well population. Section E, entitled "Personality Information," seeks information on the respondents' personality type with respect to Type A behaviors based on literature by Friedman, et al. (1982) and Theorell and Rahe (1972). The next section, "Iife Satisfaction," covers the variables of life satisfaction as described by Palmore and Kivett (1977), and Palmore and Liukart (1972). Other scales on life satisfaction were found in the literature, but this one was used because it had an activity perspective and covered change over time for a middle and late aged population. Other scales focused primarily on the retired and aged population (Neugarten, et al., 1961 and Adams, 1969). The life satisfaction variables are based on three Cantril Ladders (1965) and questions on numbers of hours per week engaged in various activities (Palmore \& Kivett, 1977). The final section of the questionnaire is 
entitled "Risk Factor Management" and covers variables affecting prevention of further cardiac problems as described by the Multiple Risk Factor Intervention Trial Research Group (1982) and Pelletier (1975). Finally, the subjects were asked which risk factors they would most like to improve or change. The format of the overall questionnaire was based on the Milwaukee Cardiovascular Iife Quality Questionnaire, which was published by Rimm, Hartz, Kalbfleisch, Anderson, and Hoffman (1980). Questionnaire data were anonymous. To assure this, the questionnaires were coded numerically and then distributed to all individuals during their rehabilitation sessions at the YMCA. Subjects were requested to return the questionnaires within 14 days to the office of the Cardiac Rehabilitation Program staff at the Westside YMCA.

\section{Analysis of Data}

The data obtained from the questionnaires were analyzed in order to answer the questions posed in this study. Demographic and medical information was presented in frequencies and percentages as background information for the study.

In order to answer Question 1 - did changes occur in life satisfaction - data from the "Life Satisfaction" 
section of the questionnaire were analyzed. Frequencies and percentages for all variables were calculated, for pre- and post-hospitalization. T-tests and non-parametric signed rank tests were performed on the variables of life satisfaction to compare before versus after hospitalization.

The responses from the "Activity Balance Satisfaction" section were analyzed to answer Question 2 regarding changes in activity balance satisfaction. Frequencies and percentages were calculated for pre- and post-hospitalization data. The degree of change in satisfaction of activity balance from pre- and post-hospitalization was assessed using the McNemar tests for symmetry.

Question 3 related to the change in the balance of daily work, leisure, and self/family care activities pre-and post-hospitalization. Data from the "Activity Balance" section of the questionnaire were analyzed to answer this question for all continuous variables. Means or medians, and standard deviarions were determined. Paired sample $t$-tests were performed to compare daily hours engaged in each variable before with after hospitalization.

The information in the "Personality Data" section of the Life Satisfaction Questionnaire was studied to answer Question 4, which related to personality changes, 
specifically feelings of time constraints and Type A behavior. Frequencies and percentages were calculated for both personality issues. Means and standard deviations were calculated, and paired sample t-tests and Wilcoxon signed rank tests were performed on the data to identify degree of change from pre- and post-hospitalization.

Question 5 - did risk factor management skills change pre- and post-hospitalization? - was answered from data collected on that section of the Life Satisfaction Questionnaire. Percentages of respondents showing change were calculated and subjective data from a subjective fill-in section were assessed.

Changes in perceived health, Question 6, were analyzed from the questionnaire data relating to self-rated health. Frequencies and medians were calculated. The Wilcoxon signed rank test was performed to assess change from pre- to post-hospitalization.

Question 7 asked whether significant differences existed between life satisfaction and variables relating to health and and activity. These variables were: self-rated health, organizational activity, social activity, productive hours, and sexual enjoyment. The correlations between these variables were analyzed using the spearman rank correlation coefficients. 
To answer Question 8, relationships between activity balance statisfaction and activities of daily IIving (work, non-strenuous exercise, strenuous exercise, and self/family care) were analyzed. Interrelationships between the variables were studied using stem and leaf plots to determine summary statistics, including percentages and medians. T-tests and Wilcoxon signed rank tests were performed to compare differences and determine statistical significance.

Question 9 asked about the relationship between life satisfaction and activity balance satisfaction. A discriminant analysis could not be performed on the variables of life satisfaction and activity balance satisfaction as the cell sizes were too small. 
CHAPTER FOUR

\section{RESULTS}

Seventy self-administered "Life Satisfaction Questionnaires" were distributed to participants in the Westside YMCA Cardiac Rehabilitation Program. Forty-eight questionnaires (69 percent) were returned. Forty-three or 90 percent of those that were returned could be used for the purpose of this study. Usable questionnaires were those which indicated that the respondent indicated that he/she had been hospitalized 1) for a Myocardial Infarction and/or Bypass surgery on survey question A.1.; and 2) initially for cardiac problems at least six months prior to the date on which the questionnaire was completed (Survey Question 2). As the questionnaire was distributed during the Cardiac Rehabilitation Program classes, all respondents were currently in a rehabilitation program, and all therefore met the third requirement for this study, which was current or previous participation in a cardiac rehabilitation program. The information obtained from the questionnaires was analyzed using SYSTAT: The System for statistics (Wilkinson, 1986). In most cases tables are included for each question. Some data which could be easily understood, were discussed in paragraph 
form in the narrative portion of this chapter. Frequencles and percentages for all categorical variables were determined, as were central tendency varlables (mean or median, and standard deviation) for all continuous variables. Medians were used for some continuous variables as the distributions were skewed. Data were attained on: hospitalization/rehabilitation, demographics, medical and smoking status, dally activities, personality information, life satisfaction, and risk factors.

Hospitalization Data

\section{Diagnosis}

of the 48 total respondents, five (10.4 percent) indicated hospitalization for cardiac problems other than myocardial infarction or bypass surgery, and were eliminated from the study. Of the 43 remaining respondents, 18 ( 37.5 percent) indicated hospitalization for myocardial infarction, 15 ( 31.3 percent) indicated bypass surgery, and ten (20.8 percent) reported hospitalization for both myocardial infarction and bypass surgery (see Table 1). 
Table 1

Diagnosis of Respondents at Hospitalization

$\begin{array}{lll}\text { Category } & \text { \# of } & \% \text { of } \\ & \text { Respondents } & \text { Respondents }\end{array}$

\begin{tabular}{lcc}
\hline Myocardial Infarction & 18 & $37.5 \%$ \\
Bypass Surgery & 15 & $31.2 \%$ \\
Both MI and Bypass Surgery & 10 & $20.8 \%$ \\
Other Cardiac Problems & 5 & $10.4 \%$ \\
\hline Total & & \\
\hline
\end{tabular}

Note: Respondents under "other cardiac problems" category were eliminated from the study. 


\section{Time Post Hospitalization}

Thirteen ( 30.2 percent) of the respondent sample were five years or less post-first hospitalization at the time that the questionnaires were completed, and 30 (69.8 percent) were more than five years post-first hospitalization for myocardial infarction and/or bypass surgery.

Demographic Data

$\underline{\text { Sex }}$

Of the total 43 who constituted the final sample, ten (23.3 percent) of the respondents were female and 33 (76.7 percent) were male.

\section{Age}

None of the respondents was younger than 39 years of age. There were three ( 7.0 percent) in the $40-49$ year age range, 11 (25.6 percent) in the 50-59 year range, 20 (46.5 percent) in the 60-69 year range, eight (18.6 percent) in the 70-79 year range, and one respondent (2.3 percent) was 80 years old or above. More than 70 percent $(72.1)$ of the respondents were between 50 and 69 years of age. 


\section{Ethnicity}

Forty-two respondents indicated Caucasian as their ethnic group. One respondent indicated Black. There were no Asian Americans, Latin Americans or other ethnic groups indicated in this sample.

\section{Marital Status}

Thirty-one (72.1 percent) of the respondents reported that they were currently married, five individuals ( 11.6 percent) were divorced, three $(7.0$ percent) were single, one (2.3 percent) was widowed, and three ( 7.0 percent) indicated other.

\section{Level of Education}

of the 43 respondents, none had less than a high school degree. Twelve individuals (27.9 percent) had high school degrees, two ( 4.6 percent) graduated with vocational/professional degrees, 2 ( 4.6 percent) had associate degrees, 12 (27.9 percent) graduated with bachelor's degrees, and 15 individuals (34.9 percent) had graduate degrees. The majority of respondents held higher education degrees. 


\section{Family Income}

Two respondents ( 4.6 percent) reported an annual family income level of less than $\$ 10,000$, six respondents (13.9 percent) reported a level of $\$ 10,000-29,000$, elght (18.6 percent) were at the $\$ 30,000-49,000$ level, and 27 individuals ( 62.8 percent) reported an annual family income of $\$ 50,000$ or above. The respondents in this sample were highly skewed toward the upper income bracket.

\section{Employment Status}

At the time that the questionnalres were completed, six Individuals (13.9 percent) were employed part-time (less than thirty hours per week), 19 (44.2 percent) of the respondents were employed full time, three 17.0 percent) were not employed and 15 ( 34.9 percent) were retired.

\section{Medical Information}

Health problems related to coronary heart disease as indicated by the MREITRG (1982) were ourveyed for before and after hospitalization status. The total 
number of health problems listed on the questionnaire was eight. Before the first hospitalization 23 individuals (53.5 percent) reported at least two health problems related to coronary heart disease, and one respondent indicated that all eight factors were evident. After hospitalization (at the time the questionnaires were completed), 51.2 percent (22 respondents) indicated that they did not suffer from any health problems related to coronary heart disease, and 12 respondents $(27.9$ percent) reported two or more related health problems (see Table 2).

Cigarette, pipe, and cigar smoking behaviors were tabulated for before and after first hospitalization. In the year before the first hospitalization 65.1 percent (28 respondents) indicated that they did not smoke. Ninety-five percent ( 41 respondents) reported that they did not smoke at the time the questionnaires were completed, following the first hospitalization (see Table 3 ). 
Table 2

Coronary Heart Disease - Related Health Problems

\begin{tabular}{|c|c|c|c|c|}
\hline \multirow{2}{*}{$\begin{array}{l}\text { Category } \\
\text { \# Health Problems }\end{array}$} & \multicolumn{2}{|c|}{ Before } & \multicolumn{2}{|c|}{ After } \\
\hline & \# & $\underline{\not}$ & \# & $\%$ \\
\hline 0 & 10 & 23.3 & 22 & 51.2 \\
\hline 1 & 10 & 23.3 & 9 & 20.9 \\
\hline 2 & 11 & 25.6 & 6 & 14.0 \\
\hline 3 & 5 & 11.6 & 4 & 9.3 \\
\hline 4 & 3 & 7.0 & 2 & 4.6 \\
\hline 5 & 3 & 7.0 & 0 & 0.0 \\
\hline 6 & 0 & 0.0 & 0 & 0.0 \\
\hline 7 & 0 & 0.0 & 0 & 0.0 \\
\hline 8 & 1 & 2.2 & 0 & 0.0 \\
\hline Total & 43 & 100.0 & 43 & 100.0 \\
\hline
\end{tabular}


Table 3

Amount Smoked by Respondenta

\begin{tabular}{lcccc}
\hline Category & \multicolumn{2}{c}{ Before } & \multicolumn{2}{c}{ After } \\
\# Cigarettes daily & \# & $\frac{8}{\%}$ & \\
\hline Never Smoked & 28 & 65.1 & 41 & 95.4 \\
$0-10$ & 3 & 7.0 & 1 & 2.3 \\
$11-20$ & 2 & 4.7 & 1 & 2.3 \\
$21-40$ & 5 & 11.6 & 0 & 0.0 \\
over 40 & 5 & 11.6 & 0 & 0.0 \\
\hline Total & & & & 100.0 \\
\hline
\end{tabular}

Note: \# cigarettes also includes pipesful or cigars. 
Question 1

Data obtained to answer Question 1, which asked whether changes occurred in life satisfaction pre- and post-hospitalization, were collected from responses to the Life Satisfaction portion of the Life Satisfaction Questionnaire (Appendix B). The varlables were: self-rated health, organizational activity, social activity, productive hours, sexual enfoyment, and perceived life satisfaction. The variable of self-rated health was also addressed independently in Question 6. Data on life satisfaction were derived from the number of hours that participants were involved in various activities. Due to skewed data, medians were used for these data to provide a valid statistical presentation of participants' responses.

\section{Self-Rated Health}

Self-rated health data were collected to assess Iife satisfaction in Question 1 , as well as independently to answer Question 6 regarding perceived health. The subjects were asked to rate their perceptions of their health levels for pre- and post-hospitalization on a scale of zero to nine, with zero being the most serious 11lness, and nine being perfect health. For the 43 subjects, the median before hospitalization was six. 
After hospitalization, the median was seven. Formal tests showed a significant difference between before and after hospitalization ( $p<.025$, using the Wilcoxon signed rank test). This demonstrated that, in retrospect, respondents felt that they were healthier after hospitalization than before hospitalization (see Tables 4 and 5 ).

\section{Organizational and Soctal Activity}

When asked about the number of hours spent at religlous services and other group meetings weekly, the median number of hours reported by the respondents was 1.00. There was no change in median hours spent before versus after hospitalization. There was also no significant difference in social activity hours spent before and after hospitalization. The medians both before and after hospltalization were 6.00 .

\section{Productive Time}

Before hospitalization, the median number of hours spent weekly in work activities was 30.00. After hospitalization, the median dropped to 15.00 , exactly 
Table 4

Iife Satisfaction - Self-Rated Health

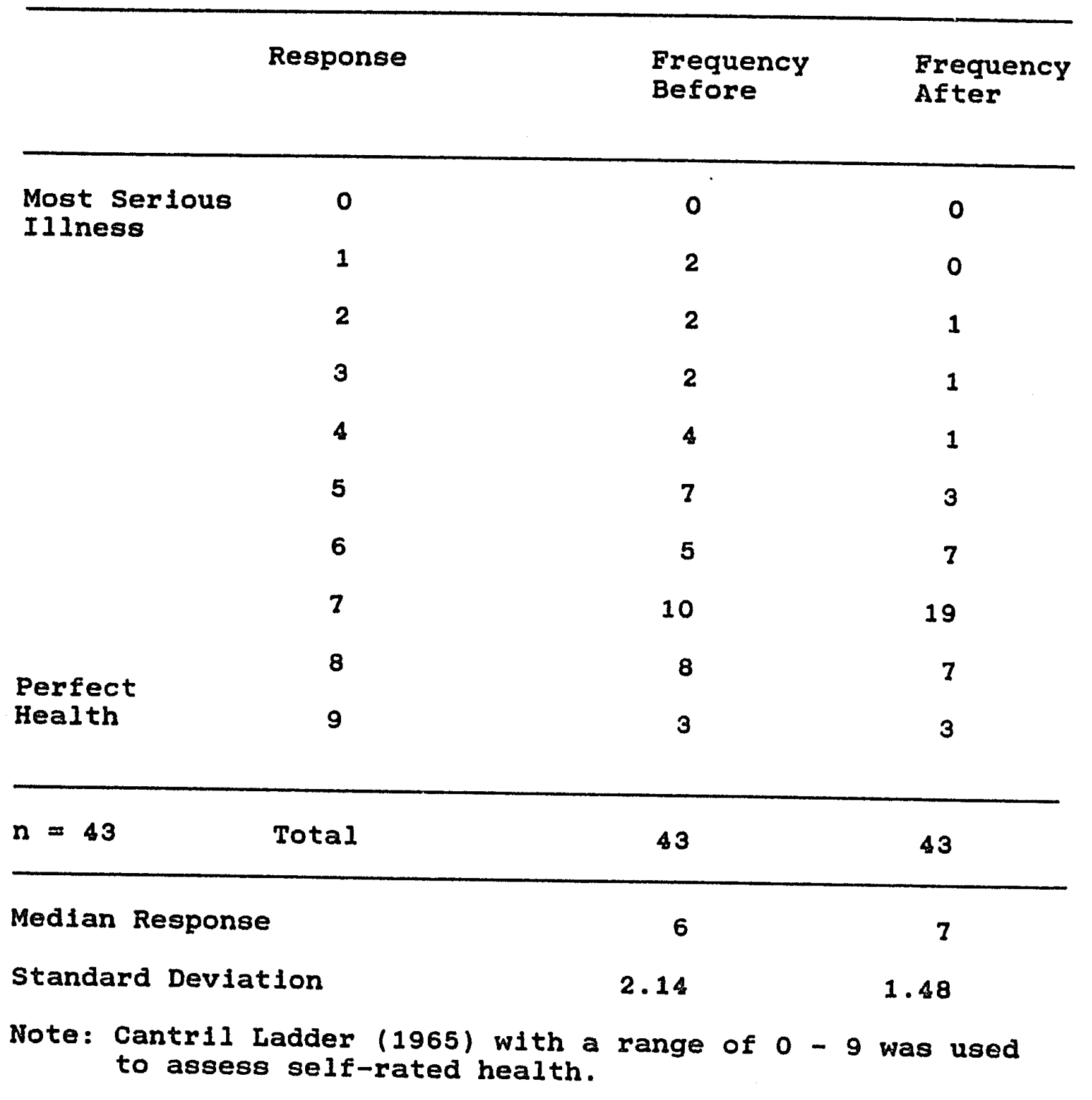


Table 5

Life Satisfaction - Self-Rated Health Differences

\begin{tabular}{|c|c|c|}
\hline & $\begin{array}{l}\text { Before - After } \\
\text { Scores }\end{array}$ & Frequency \\
\hline \multirow[t]{6}{*}{ More Heal thy } & -6 & 1 \\
\hline & -5 & 3 \\
\hline & -4 & 2 \\
\hline & -3 & 5 \\
\hline & -2 & 4 \\
\hline & -1 & 5 \\
\hline \multirow[t]{6}{*}{ No Change } & 0 & 10 \\
\hline & 1 & 7 \\
\hline & 2 & 0 \\
\hline & 3 & 0 \\
\hline & 4 & 1 \\
\hline & 5 & 0 \\
\hline Less Healthy & 6 & 1 \\
\hline$n=43$ & Total & 43 \\
\hline
\end{tabular}


half of the previous amount. There was a significant decrease in the number of hours spent in productive pursuits such as housework and work for pay before versus after hospltalization $(p=.001$, using the wilcoxon signed rank test).

\section{Sexual Enjoyment}

The participants were asked to rate their level of sexual enjoyment before and after hospitalization on a zero to nine scale, with zero being no enfoyment and nine being maximum enfoyment. The median before hospitalization was reported to be 3.00 , and after was reported to be 2.00 . The respondents enfoyed their sex lives less after hospitalization. The difference reached statistical significance at $p=.007$, using the Wilcoxon signed rank test.

\section{Perceived Life Satisfaction}

The respondents were asked to indicate the levels of their percelved 11 fe satisfaction before and after hospitalization, with zero as dissatisfied and nine as very satisfied. The median was 6.00 for before and 7.00 after hospitalization (see Table 6). The participants were more satisfied with their lives after the first 
hospitalization and rehabilitation for cardiac problems; however, the differences did not reach significance at $\mathrm{p}=.064$, using a non-parametric wilcoxon signed-rank test.

Question 2

Question 2 of this study, which asked whether particlpants were satisfied with their activity balance before versus after hospitalization, was answered from data obtained from the last question of the "Daily Activity Information" portion of the Life Satisfaction Questionnaire, relating to satisfaction with balance of activities before and after hospitalization. Before hospitalization, 20 respondents expressed dissatisfaction with their activity balance, and 23 reported being satisfled with their activity balance. After hospitalization, 13 were dissatisfied, and 30 were satisfied (see Table 7 ). Twelve respondents demonstrated change from dissatisfied to satisfied, when the McNemar tests for symmetry were applied to responses of the activity balance satisfaction question. This result was not found to be significant $(p<.09)$. 
Table 6

Percelved Life Satisfaction

\begin{tabular}{lccc}
\hline & Response & Before & After \\
\hline Dissatisfied & 0 & 1 & 1 \\
& 1 & 1 & 0 \\
& 2 & 1 & 2 \\
& 3 & 1 & 2 \\
& 4 & 3 & 2 \\
Very & 5 & 11 & 5 \\
Satisfied & 6 & 6 & 12 \\
\hline Standard Deviation & 7 & 13 & 6 \\
\hline & 8 & 2 & 8 \\
\hline & 9 & 4 & 25 \\
\hline & & 43 & 43 \\
\hline
\end{tabular}


Table 7

Activity Balance Satisfaction

\begin{tabular}{ll}
\hline Category & \#espondents \\
& Unsatisfied After \\
& Hospitalization
\end{tabular}

\# Respondents Satisfied After Hospitalization Total

\# Respondents Unsatisfled Before Hospitalization

8

12

20

* Respondents Satisfied Before Hospitalization

5

18

23

Total

13

30

43

McNemar Symmetry Chi-square Test:

Chi Square $=2.88$

$\mathrm{DF}=1$

$\mathrm{p}$ Value $=.09$

Note: Difference in activity balance satisfaction before versus after hospitalization was not statistically significant. 
Question 3

Data were analyzed from the "Daily Activity Information" portion of the Life Satisfaction Questionaire (Appendix B) to answer Question 3: Did changes occur in the balance of daily work, leisure, and self/family care pre- and post-hospitalization? The last question in the Daily Activity Information section of the questionnaire related specifically to Question 2, regarding activity balance satisfaction, and was discussed above. Daily activity information was reported in number of hours per day spent in work, leisure, self/family care, and sleep based on a typical 24 hour day. For all continuous variables, means or medians, and standard deviations were determined. Medians were used for some continuous variables because the distributions were skewed. Tests to compare the changes of daily activity hours of the variables for before and after first hospitalization were also performed. Due to the skewed distribution of some variables, nonparametric tests (signed rank tests) were run on those variables. Paired sample t-tests were performed on the other continuous variables. 


\section{Work Hours}

Respondents were asked to indicate the number of hours per day they were engaged in work activities, based on a typical 24 hour day (Monday through Friday). Fourteen of the respondents apparently answered this question on a weekly basis instead of reporting the daily hours requested. Those reponses were therefore dropped. Of the 29 cases used, the mean was 7.45 hours spent in work daily before hospitalization and 5.24 after hospitalization. On the average, the respondents worked 2.21 less hours per day after hospitalization than they did before hospitalization, with a standard deviation of 2.87. A paired sample $t$-test was performed to compare daily hours worked before and after hospitalization $(t=$ 4.14; df $=28$ ), which showed a significant change in daily hours worked pre- and post-hospitalization $(p<.0005)$.

\section{Leisure Hours}

Time spent in leisure tasks was divided into sedentary, moderate, and strenuous activity. All 49 cases were used. A mean of $3.11(S D=2.65)$ hours were reported to be spent on sedentary tasks or strict relaxation daily before hospitalization. Although after 
hospitalization, the mean increased to 3.87 hours $(S D=$ 2.48), a paired sample t-test did not show a statistically significant change from before to after hospitalization with respect to sedentary activity.

For leisure activities requiring moderate exertion, the mean was 2.22 hours per day $(S D=2.20)$ before hospitalization, and $2.34(S D=2.01)$ after hospitalization. Again, the paired sample t-test of the 43 cases showed no significant change.

A significant change was found with respect to strenuous exercise hours spent. Before hospitalization, the respondents spent a mean of 0.86 hours daily on strenuous activity (SD $=2.20)$, and after hospitalization the mean increased to 1.35 hours daily $(S D=1.04)$. The respondents spent a mean change of .61 more hours engaged in strenuous activities after hospitalization (SD $=.93$ ). The paired sample $t$-test comparing before and after hospitalization showed a significant increase in strenuous exercise hours spent after hospitalization, at $t=4.27$, $\mathrm{df}=42, \quad \mathrm{p}<.005$.

To summarize, it was determined that although there was not a significant change before and after hospitalization on sedentary or moderate leisure activity, there was a significant increase in strenuous activity on a daily basis following hospitalization, possibly with the incorporation of the cardiac 
rehablittation program into the respondents' lifestyles.

\section{Self-Care and sleep Hours}

Self- or family-care time spent dally did not change substantially from before to after first

hospitalization. The mean hours spent in self- or family-care before hospitalization were reported to be $1.70(S D=2.17)$, and after hospitalization as 1.38 (SD $=$ $1.63)$.

The number of hours that respondents slept daily also did not change significantly after hospitalization. The mean before hospitalization was 6.54 hours $(S D=1.50)$ and after hospitalization was $6.55(S D=1.49)$.

\section{Vacation Time}

of the 43 respondents, there was a mean of 9.07 weeks of vacation taken during the five years prior to completion of the questionnaires. The standard deviation was 8.26. Hospitalization time was not indicated for inclusion in these data. 
Question 4

Personality information was obtained from that section of the Life Satisfaction Questionnaire (Appendix B), in order to answer Question 4 of this study: Did scores on a personality inventory indicate possible Type A behavior characteristics pre- and post-hospitalization? Two aspects of Type A behavior were studied: feelings of time constraints and words relating to possible Type A behavior.

\section{Feelings of Time Constraints}

When asked whether they were often rushed, or felt time constraints in their daily lives, two people 14.6 percent) did not respond, eight (18.6 percent) responded that they never felt rushed, 16 (37.2 percent) felt rushed sometimes, and 17 ( 39.5 percent) always felt rushed before they were hospitalized for cardiac problems. When asked about after hospitalization status, there was one non-response, 13 indicated that they never felt rushed (30.2 percent), 23 (53.5 percent) were rushed some of the time, and only six (1.3.9 percent) always felt rushed (see Table 8). There was a significant decrease in feelings of time constraints after hospitalization as compared with before hospitalization at $p<.006$, using 
Table 8

Feelings of Time Constraints

\begin{tabular}{lcccr}
\hline Category & \multicolumn{2}{c}{ Before } & \multicolumn{2}{c}{ After } \\
& $\#$ & $\%$ & $\#$ & 2.3 \\
\hline No Response & 2 & 4.6 & 1 & 30.2 \\
Never & 8 & 18.6 & 13 & 53.5 \\
Sometimes & 16 & 37.2 & 23 & 13.9 \\
Always & 17 & 39.5 & 6 & 100.0 \\
\hline Total & 43 & 100.0 & 43 & \\
\hline
\end{tabular}


the wilcoxon signed rank test.

\section{Type A Behavior}

Data on Type A behavior were collected from Question 2 of the "Personality Information" portion of the life Satisfaction Questionnaire (see Appendix B). Participants were asked to mark words from a list of personality traits which applied to their respective temperaments. The words which were related to Type A behavior ("moody," "fast-paced," "competitive," and "stressed") were given the number one, and those which did not relate to Type A behavior ("even-tempered," "slow-paced," "noncompetitive," and "relaxed") were given a zero. Each participant was then given a score based on the total number of points. The maximum score was four and a different score was calculated for before and after hospitalization. Before hospitalization, 41.8 percent of the participants reported three or more personality traits associated with Type A behavior, while only 13.9 percent indicated three or more after hospitalization (see Table 9). The mean number of responses reflecting Type A personality was $2.23(\mathrm{SD}=1.02)$ before hospitalization, and 1.44 after hospitalization (SD = 1.07). There was a highly significant decrease in 


\section{Tabie 9}

Type A Behavior - Personal1ty Indicators

\begin{tabular}{lrrrr}
\hline Category & \multicolumn{2}{c}{ Before } & \multicolumn{2}{r}{ After } \\
\# Type A Responses & $\#$ & 8 & $\#$ & \\
\hline 0 & 2 & 4.6 & 11 & 25.6 \\
1 & 8 & 18.6 & 9 & 20.9 \\
2 & 15 & 34.9 & 17 & 39.5 \\
3 & 14 & 32.5 & 5 & 11.6 \\
4 & 4 & 9.3 & 1 & 2.3 \\
\hline Total & 43 & 100.0 & & 100.0 \\
\hline
\end{tabular}


traits affillated with Type A behavior after hospltalization at $p<.001$, using a paired sample $t$-test and Wilcoxon signed rank test.

\section{Question 5}

In response to Question 5; regarding risk factor management skills with respect to diet, smoking exercise, stress, and alcohol consumption pre- and post-hospitalization; data were collected from the "Risk Factor Management" portion of the Life Satisfaction Questionnaire (Appendix B). Information on managing risk factors had been provided as an integral part of the cardiac rehabilitation program for the respondents previous to their completing the Life Satisfaction Questionnaire.

The participants were presented with a list of risk factors considered to be important with respect to coronary heart disease (MRFITRG, 1982). They were asked whether they felt that they had changed in the performance of the health care practices which were Iisted on the questionnalre (see Table 10). The respondents reported that they had improved in most areas of risk factor management after hospitalization and participation in the rehabilitation program which emphasized these changes. The most 


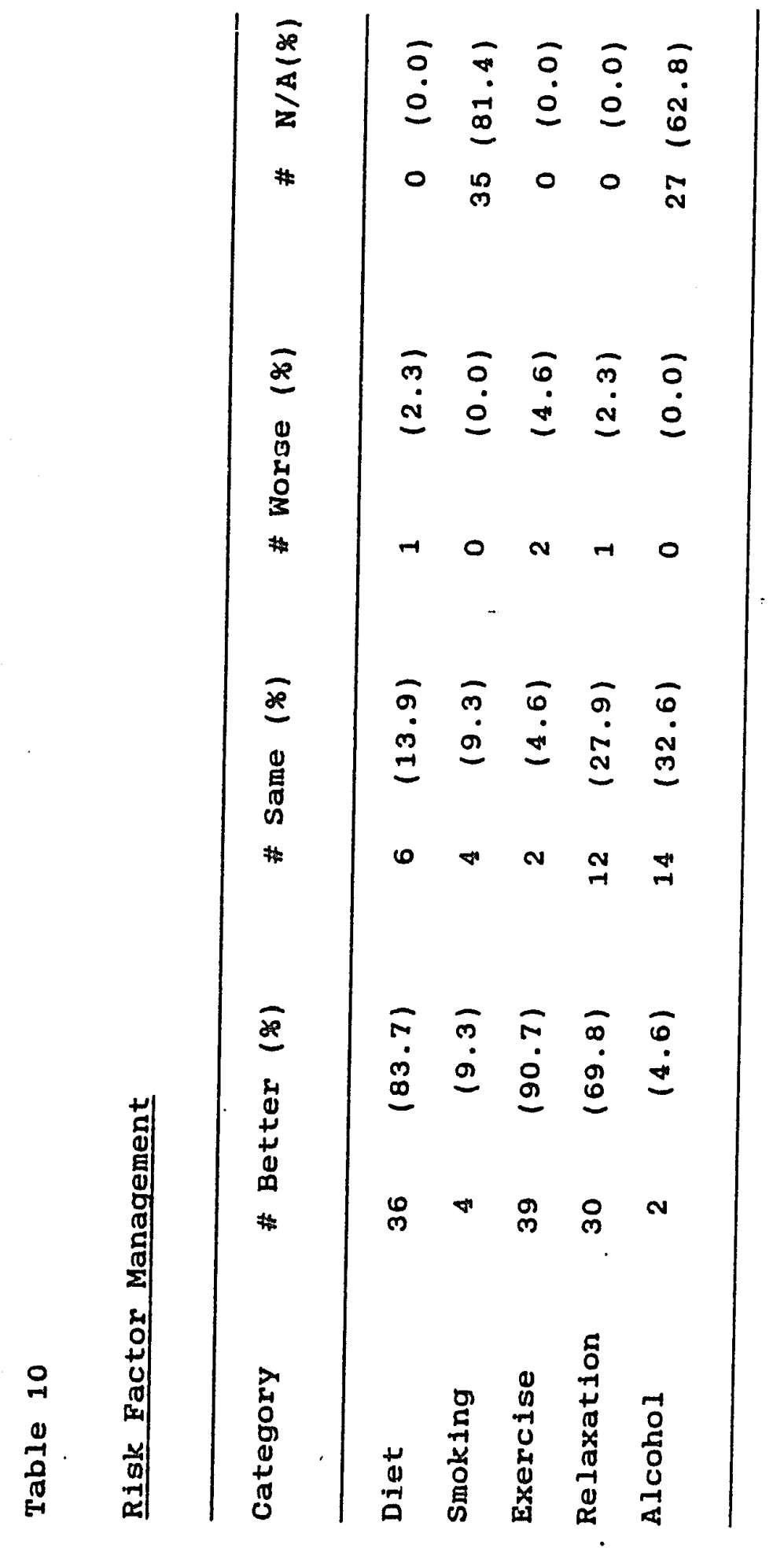


significant improvements occurred in increased exercise levels ( 90.7 percent improvement) and diet (83.7 percent improvement). When asked which areas they would most like to improve, the area most mentioned was diet, reported by 25 respondents. Diet was also indicated as the area which was the most difficult to improve, as reported by 27 respondents. Relaxation and exercise habits were also reported as difficult to change.

\section{Question 6}

Self-rated health data were collected in order to answer Question 6: Did changes occur in perceived health pre- and post-hospitalization? As stated in the section regarding Question 1 above, self-rated health was also a variable of life satisfaction as described in this study. As stated in the section on Question 1 above, the subjects were asked to rate their perceptions of their health levels for pre- and post-hospitalization on a scale of zero to nine, with zero being the most serious illness, and nine being perfect health. The median before hospitalization was found to be six. After hospitalization, the median was found to be seven. As stated earlier, a significant difference was found between pre- and post-hospitalization ( $p<.025$, using the wilcoxon signed rank test). This demonstrated that, in 
retrospect, respondents felt that they were healthier after hospltalization than before hospitalization (see Tables 4 and 5 ).

\section{Question 7}

To answer Question 7 , the relationships between the differences in variables relating to health and activity (self-rated health, organizational activity, social activity, productive hours, and sexual enjoyment) pre- and post-hospitalization were correlated with each other, and with life satisfaction. By performing these tests, the correlations ketween specific aspects of life satisfaction were addressed. The question of whether one specific type of activity has a stronger impact on lize satisfaction than any other was studied.

Relationships between the health and activity variables in the Life Satisfaction section of the questionnaire were determined using the spearman rank correlation coefficients. The variables of self-rated health, organizational activity hours, social activity hours, productive hours, sexual enfoyment, and life satisfaction were ranked and compared with each other and with the score of the difference in life satisfaction pre- and post-hospitalization. The correlation coefficient $r \underline{\underline{g}}=.34$ or greater, indicated that there was 
significance at the .05 level.

The differences between retrospective reports of before and after hospitalization were ranked and tested against each other for each of the variables (see Table 11). A strong positive correlation was found between the difference in life satisfaction and self-rated health $(r \underline{s}=.64)$. The relationships between the life satisfaction difference and the social activity difference ( $\mathrm{r} \underline{\underline{s}}=.65$ ) and, sexual enjoyment difference $(r \underline{\underline{s}}=.38)$ were also strongly significant. Self-rated health difference was strongly correlated with social activity difference $(r s=.57)$ and with sexual enjoyment difference ( $\mathrm{r} \underline{\mathrm{S}}=.3 \hat{4})$, as well as with life satisfaction.

The strongest correlations were evident between life satisfaction and self-rated health. Respondents felt healthier after hospitalization than before hospitalization. There were also strong positive correlations between the differences pre- and post-hospitalization with respect to these two varlables and social activity hours and sexual enjoyment. Correlations among other variables were not statistically significant. 


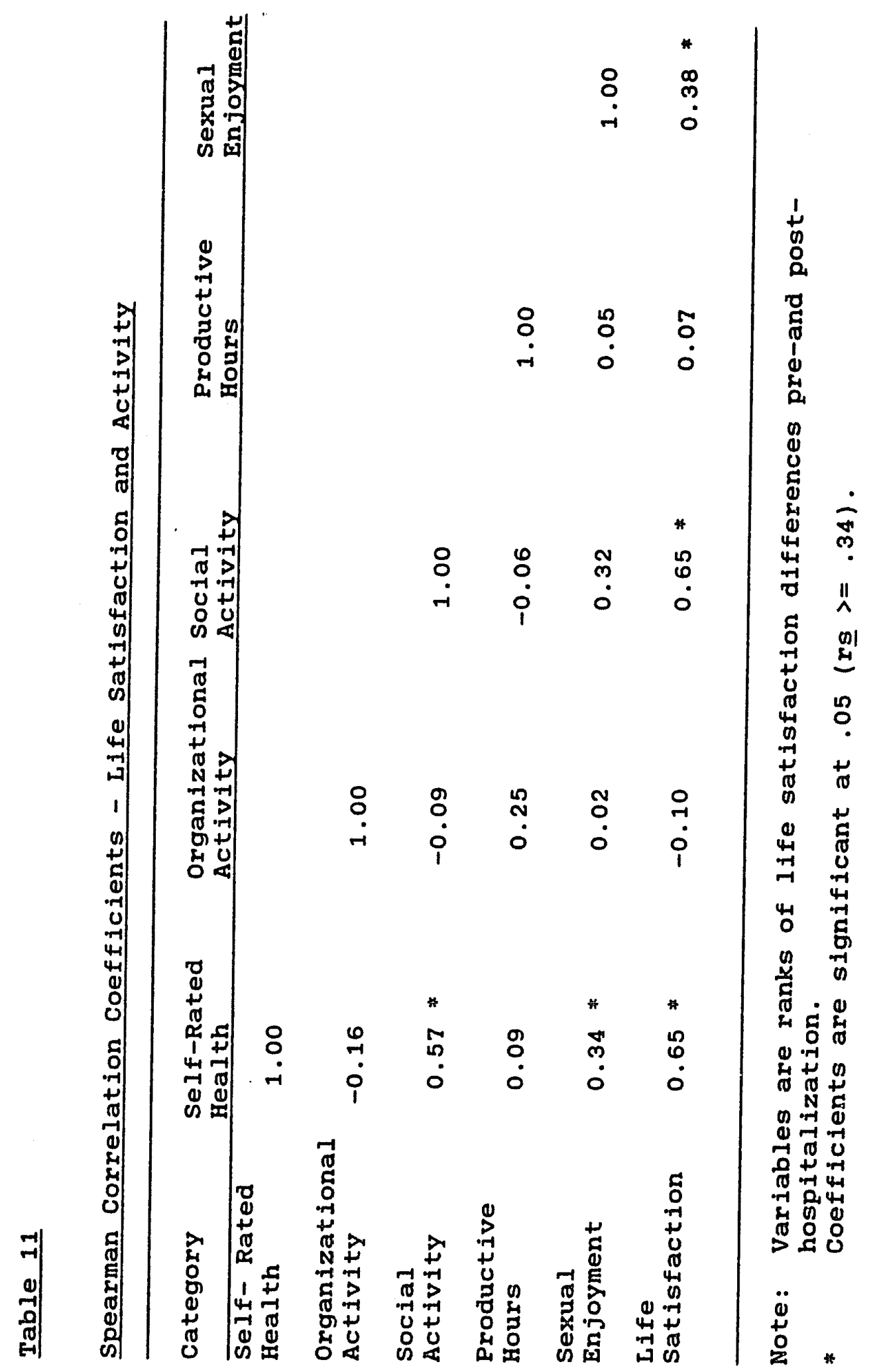




\begin{abstract}
Question 8
Data were obtained from the "Daily Activity Information" portion of the Life Satisfaction Questionnaire (Appendix B) to answer Questions 2 and 3: regarding whether change occurred in the balance of daily work, leisure and self/family care activities pre- and post-hospitalization; and whether change occurred in the satisfaction with that balance before and after hospitalization. Question 8 was answered with the following formal statistical tests which were conducted on activities of dally living (work, leisure, and self/family care), and their relationships to activity balance satisfaction.

Two types of statistical tests were performed to look at the relationships between each type of activity (work, leisure, and self/family care) and satisfaction with activity balance. The stem and leaf plots were used to determine summary statistics, including the median percentage of hours in each activity before versus after hospitalization as grouped by activity balance satisfaction before and after hospitalization. T-tests were performed on these variables, but were sensitive to outliers. The Wilcoxon signed rank (non-parametric) tests were performed to compare the differences and to determine statistical significance in percent of hours in each activity before versus after hospltalization, as
\end{abstract}


grouped by activity balance satisfaction before and after hospitalization.

The first variable assessed for Question 8 was activity balance satisfaction. The number and percentage of hours worked were compared. As mentioned previously, the number and percentage of hours worked decreased significantly following hospitalization. As can be seen in Table 12, the median number of hours worked decreased, regardless of whether individuals were satisfled with their activity balance before and after hospitalization. On Table 13 it can be seen that the percentage of hours worked decreased, though not significantly, after hospitalization. This occurred, however, regardless of the level of activity balance satisfaction before or after hospitalization. The change in activity level with respect to hours or percentage of hours worked did not have a statistically significant relationship with satisfaction of activity balance. Non-strenuous activity was one variable of leisure and, to partially answer Question 8, change in non-strenuous activity after hospitalization was compared with activity balance satisfaction before and after hospitalization. There was an increase in the percentage of hours spent in non-strenuous exercise (see Table 14). The increase noted was with the individuals who were satisfied 


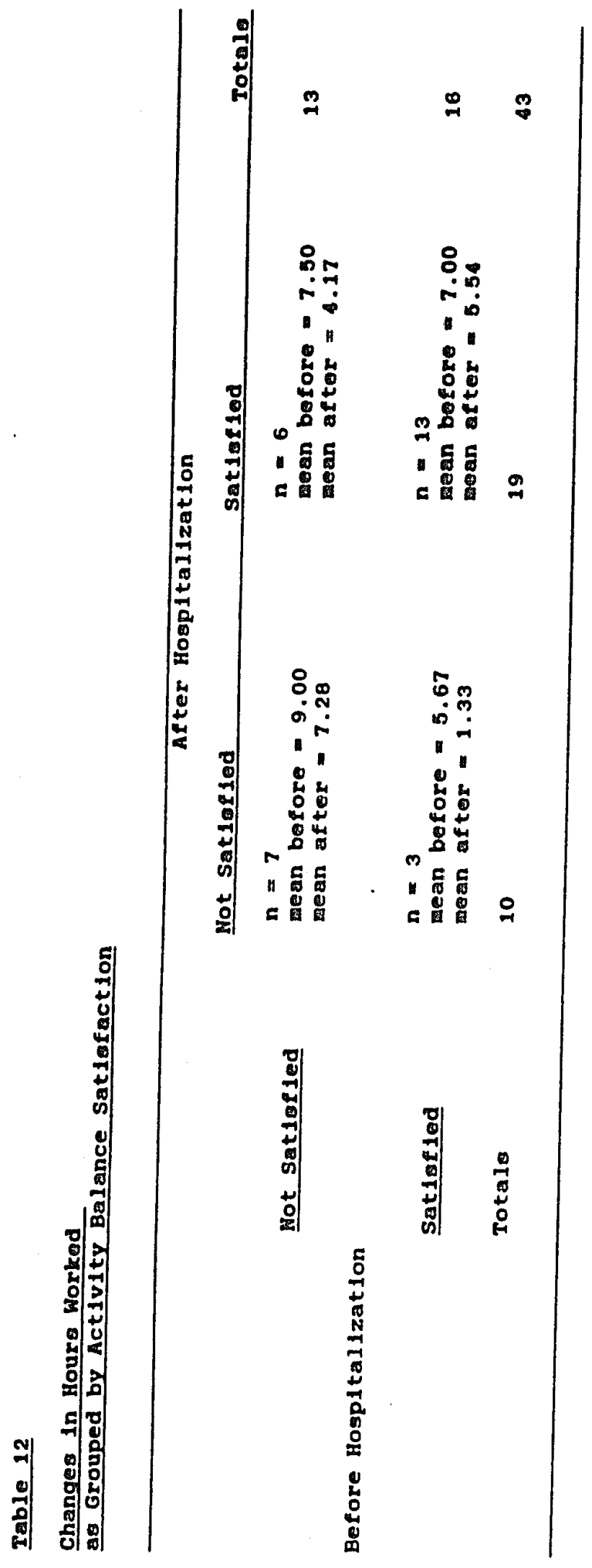




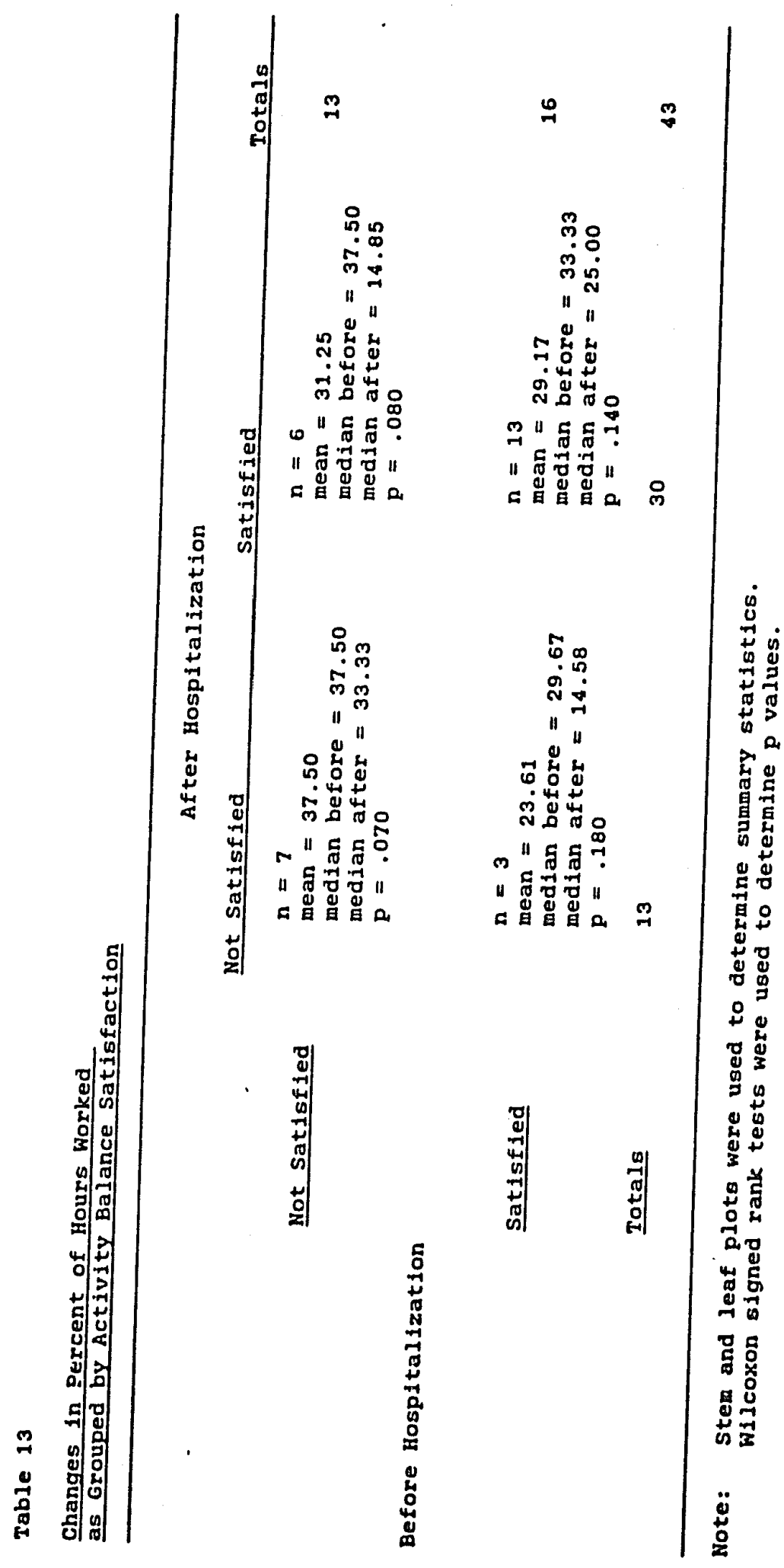




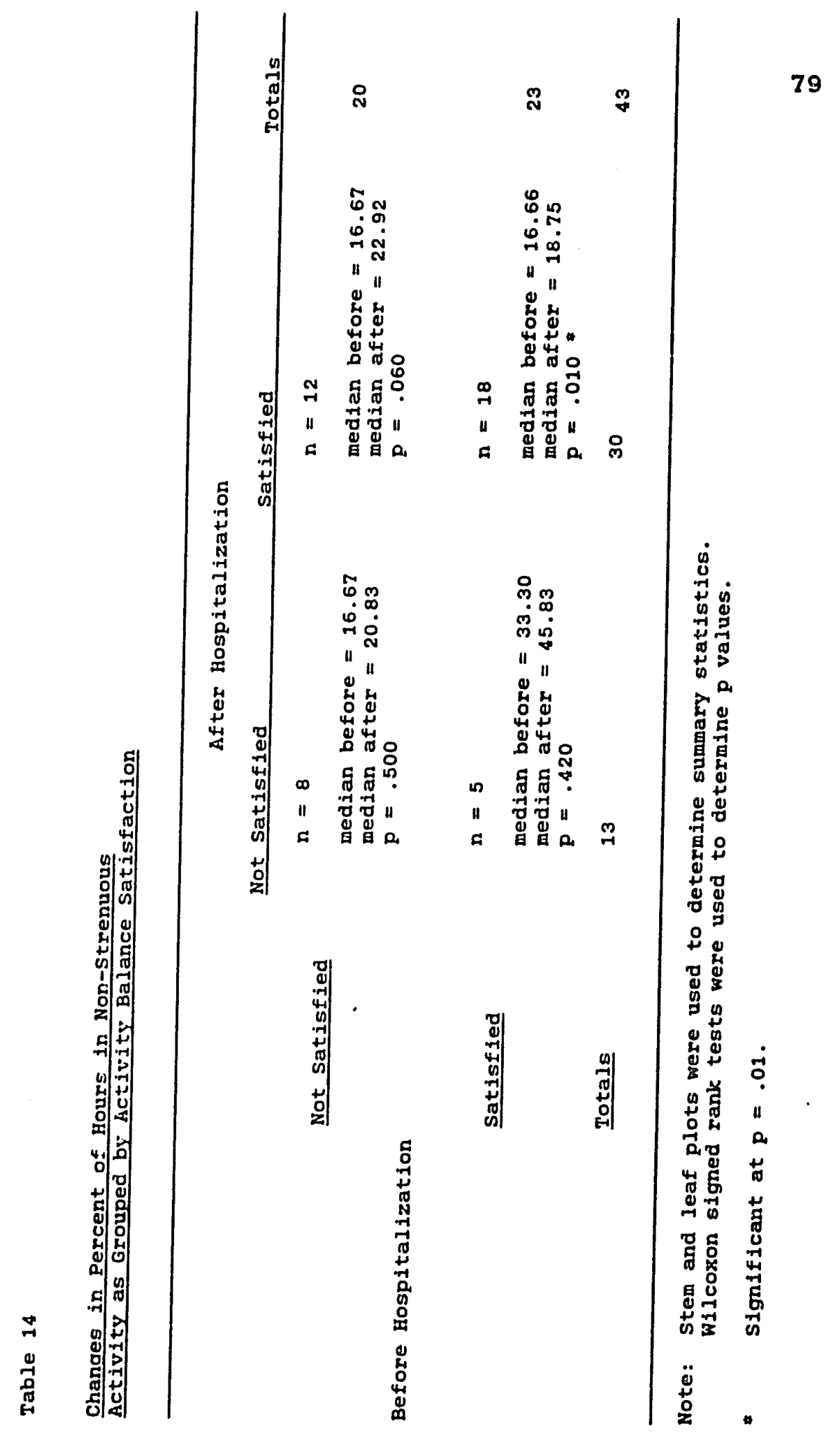


with their activity balance both before and after hospitalization $(p=.010)$. So again, this indicated that although there was a change in the activity balance, this change did not necessarily have an effect on satisfaction with activity balance.

Another aspect of leisure is strenuous activity. To partially answer Question 8, strenuous activity was compared with activity balance satisfaction to determine whether a relationship exists. There was an increase in the percentage of hours that participants were involved in strenuous exercise after hospitalization. The non-parametric tests (Table 15) indicated that the group that had the most significant increase in percentage of hours in strenuous activity was the group that was satisfied with the activity balance both before and after hospitalization.

Self-care was the last activity variable of activity balance which was compared with activity balance satisfaction to partiaily answer Question 8. Both the stem and leaf plots and the non-parametric tests showed that there was not a significant change in number of hours spent in self-care activity before versus after hospitalization. There was therefore no evidence of a relationship between self-care activity change and activity balance satisfaction. 


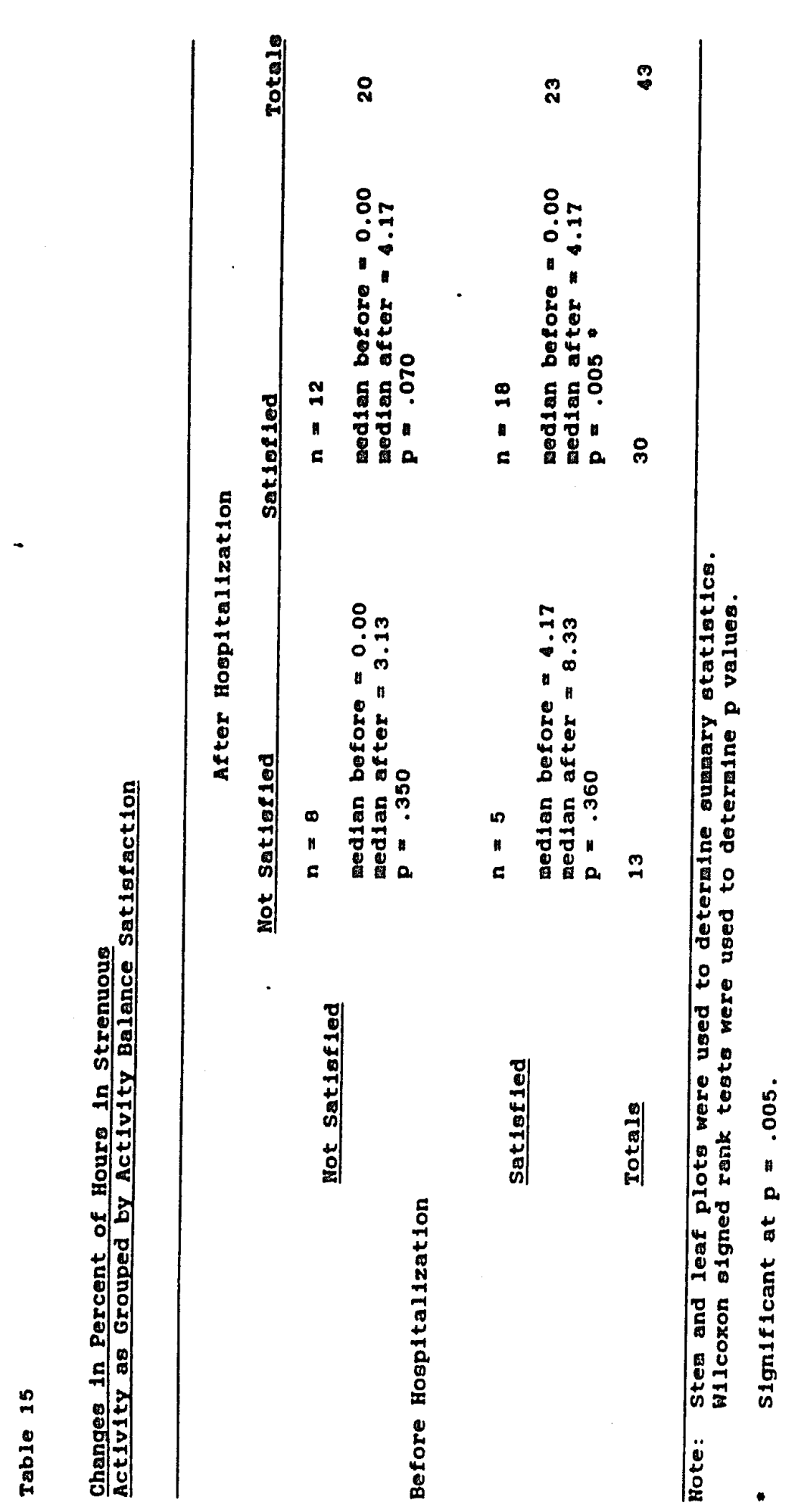


In summary, Question 8, which addressed the relationships between the varlables of activities of daily living and activity balance satisfaction was partially answered by comparing these varlables. From this research it became evident that no one varlable of activity balance (work, leisure or self/family care) individually had an impact on activity balance satisfaction, as the change in numbers or percentages of hours per week in work, non-strenuous exercise, strenuous exercise, and self-care did not signiflcantly impact on respondents' determination of activity balance satisfaction.

\section{Question 9}

Question 9 addressed the relationship between the variables of life satisfaction and activity balance satisfaction. A discriminant analysis could not be performed between life satisfaction and actlvity balance satisfaction as cell sizes were too small. Therefore, a correlation was not found. The population was divided into four groups based on activity balance satisfaction: Unsatisfied before and after, unsatisfled before and satisfied after, satisfied before and after, and satisfled before and unsatisfled after hospitalization. Means and standard deviations were determined for the 
life satisfaction difference in each of the above groups. These were based on the Wilcoxon signed ranks, in which the differences on the scale (before - after hospitalization scores) were determined for each response. The scores ranged from -4 to +4 with respect to amount of change on the scale from before to after hospitalization. The descriptive statistics show that there is no real positive relationship between respondents' feelings about life satisfaction and how satisfied they were with their activity balance. 
CHAPTER FIVE

\author{
FINDINGS, CONCLUSIONS, \\ IMPLICATIONS AND SUMMARY
}

\begin{abstract}
Activities of daily living and life satisfaction were studied in order to assess change in life satisfaction and activity balance among patients who have undergone hospitalization for cardiac surgery or myocardial infarction. An occupational performance frame of reference was used in assessing the activity balance, life satisfaction, activity balance satisfaction, and risk factor management of patients who responded to a questionnaire. Data analyzed involved the comparison of variable responses before and after hospitalization.
\end{abstract}

Question 1

Question 1 was the primary concern of this study: Did changes occur in life satisfaction, as determined by responses on a Life Satisfaction Questionnaire, pre- and post-hospitalization for myocardial infarction or cardiac surgery? Participants indicated that they were more satisfied with their lives after hospitalization (median score increased from 6.0 to 7.0 , on a Likert scale of $0-9$, with 0 indicating least satisfied and 9 indicating 
most satisfied). Though they were generally satisfied before hospitalization, they were even more satisfied afterward. This finding was difficult to compare to the literature, as no previous studies were available which compared perceptions of life satisfaction before and after hospitalization for first time cardiac patients. The Ross et al. (1981) study found an improvement in quality of life after cardiac surgery with a population of participants who were severely disabled previous to cardiac surgery. Palmore and kivett (1977) studied older individuals and found no significant change in life satisfaction among the varlous age groups in the $46-70$ year old range. A study of spinal cord injured adults (Decker \& Schultz, 1985) found that this group was slightly less satisfied with life than the well population surveyed. All studies used scales to determine life satisfaction which included variables relating to activities and level of activity change.

The current study utilized variables relating to activities and level of activity change and found that there was significant change: in self-rated health, productive time, and sexual enjoyment relative to life satisfaction after hospitalization.

Improved health was a major finding in a previous study of life satisfaction (Palmore \& Liukart, 1972). This was also found in this study, as the respondents 
indicated that they felt healthier after hospitalization, and were in the healthy range of the Iikert scale (median = 7). The relationship between self-rated health and life satisfaction was statistically significant $(p<.05)$. Self-rated health, considered to be an important variable of life satisfaction, was significantly correlated with the life satisfaction variables of social activity ( $\underline{\underline{g}}=.57$ ) and sexual enjoyment $(r \underline{s}=.34)$, as well. It was evident that respondents felt that health is a very important factor with respect to their social lives and their overall feelings of satisfaction with their lives.

The number of hours worked weekly was also significant with respect to life satisfaction. In this study there was a decrease in productive hours after hospitalization (15 hours worked weekly after hospitalization, as compared to 30 hours weekly before hospitalization, $p=.001$ ). This may indicate that working less hours had a positive effect on general life satisfaction for this group, as they had more time for social activity, exercise, and relaxation. In a previous study by Decker \& Schultz (1985), it was observed that in a group of spinal cord injured individuals, employment was strongly tied to improved quality of life. Subjects in this study were slightly less satisfied with sexual enjoyment after hospitalization (median $=2$ 
on a scale of 0-9), though they were apparently dissatisfied even before hospitalization. other studies with other disabled populations also found that there was a decrease in sexual enjoyment, though the effect this had ori life satisfaction was minimal (Palmore \& Kivett, 1977).

Question 2

Activity balance satisfaction of the balance of daily work, leisure, and self/family care activities preand post-hospitalization indicated that the participants reported positive change from pre- to posthospitalization, although not at a significant level $(p<.09)$. The Mungai study (1984) found that activity balance satisfaction was directly correlated with number of hours worked daily, as the group who worked less were more satisfied, and the group who worked more than the typical eight hour day were less satisfied with activity balance. This was not found in this study, however. Individually, the changes in work, leisure, and self/family care hours did not have an impact. Apparently the combination of decreasing work hours and increasing leisure hours positively impacted upon the respondents' feelings of satisfaction with activity balance. 
Question 3

Regarding the balance of dafly work, leisure, and self/family care activities, pre- and posthospitalization, there was a significant decrease $(\mathrm{p}<.0005)$ in hours worked daily by respondents after hospitalization. Participants reported that they were involved in 7.45 mean hours worked daily before hospitalization, and 5.24 hours daily after hospitalization. This change to a shorter work day apparently allowed time for involvement in leisure activities such as social functions and exercise, as an increase in these activities was also reported by the respondents after hospitalization.

Responses regarding leisure activities were analyzed for sedentary tasks, tasks requiring moderate exertion, and tasks requiring strenuous exercise. There was an increase in sedentary activity, but it was not significant $(p>.05)$. This was consistent with another study which indicated that there was found to be a significant increase in sedentary and homebound activities among cardiac patients after hospitalization (Barborlak, et al., 1983). On leisure activities requiring moderate exertion, again there was no signiflcant difference between before and after 
hospitalization; however, there was a significant perceived increase in strenuous activities performed daily after hospitalization $(p<.005)$. Again, this is inconsistent with the Baboriak study (1983), as an increase was found in light-to-moderate activities, but not with respect to strenuous activities, such as fast walks or tennis. It would appear that the cardiac rehabilitation program was incorporated into the current study's participants' lifestyles after hospitalization, which may have accounted for some of the reported increase in strenuous activity.

There was not a significant change in the time reportedly spent on self and family-care tasks pre- and post-hospitalization $(p>.10)$. The subjects reported spending a mean 6.5 hours sleeping per night, which did not change after hospitalization. This is 2.5 hours less than that considered to be the norm of 8.0 hours of sleep.

\section{Question 4}

Friedman, et al. (1982) discussed the personality factors which were found to be seven times more prevalent in patients with cardiac disease than with the normal population. Time urgency, excess competitiveness, and hostility were listed as primary factors. 
When asked about time constraints in this study, a majority of the respondents ( 77 percent) reported feeling rushed sometimes or always in their daily lives before hospitalization. This confirmed the Friedman et al. (1982) study with respect to this factor of Type A, or so-called "coronary-prone behavior." After hospitalization, however, the majority of the respondents reported that they felt rushed some of the time or not at all ( 84 percent). There was a significant decrease in the report of feelings of time constraints $(p<.006$ ) after hospitalization. This indicated that it may be possible to change the behaviors of time urgency, possibly with the reduction of work hours and the increase in social activity and exercise. Byrne (1981) indicated that individuals exhibiting the Type A behavior pattern tend to be heavily involved in their work, and it would reason that changing the amount time spent in work activities may affect the Type A behavior "cycle."

Type A behavior was also assessed in this study with a list of words indicating various personality traits. The words listed indicated moodiness, activity pace, competitiveness and ability to relax. A significant decrease in cumulative Type A personality traits was reported post-hospitalization ( $p<.0005)$. Again, this indicated an apparent ability of the participants in this study to change these reports of "coronary-prone 
behaviors," which Friedman et al. (1982) and others have indicated to be significant factors related to coronary disease.

According to this assessment, feelings of time constraints and Type $A$ behaviors characteristics did decrease significantly the stressful life event of hospitalization for cardiac problems.

\section{Question 5}

It is generally agreed in the literature that various factors are important in contributing to coronary heart disease (Multiple Risk Factor Intervention Trial Research Group, 1982). Though studies are conducted regularly with respect to the degree of the importance of these factors individually, at this time it is generally agreed that the interaction of all factors is significant in the occurrence of coronary heart disease, and that changes in these factors (such as improving diet to decrease cholesterol levels) have the potential benefit of reducing mortality from heart disease (Goldman \& Cook, 1984 and Glueck, 1986). It is believed, then, that individuals with this diagnosis should be educated as a matter of secondary prevention (Semmler \& Semmler, 1974 and Gleuck, 1986). All participants in the study had been educated in the risk factors as part of the 
rehabilitation program at the Westside YMCA, according to the supervisors of the program.

The participants were asked to assess their changes after hospitalization in the following areas: diet, smoking, exercise, relaxation and alcohol consumption. A vast majority of the group ( 83.7 percent) indicated that they had improved their diet and eating habits, although a large group reported that this was the most difficult area to change. They also reported improvement in the other areas: 81.4 percent were non-smokers $(48.8$ percent had never smoked), 90.7 percent reported that they had improved their exercise habits, 69.7 percent reported that they had improved their relaxation skills, and 62.8 percent of the respondents were non-drinkers.

The subjects reported that they had improved considerably in all areas of risk factor management after hospitalization. It is noteworthy that it is possible, elther independently, or within the context of a cardiac rehabilitation program, to change these risk factors and have an effect on possibly preventing or postponing further coronary problems.

\section{Question 6}

Previous studies have indicated a strong correlation between self-rated health and quality of life (Palmore \& 
Kivett, 1977). It was found in this study that there was a significant change in self-rated health after hospitalization, as respondents reported feeling healthier after hospitalization than before $(p<.025)$. This may have been an indication of the reason for the hospitalization. Westaby et al. (1979) discussed coronary artery surgery, and the degree of symptomatic relief enjoyed by a majority of the patients. The decrease in pain and other symptomology was said to directly improve quality of life and work capability. Many of the participants in this study were, in fact, hospitalized for this type of surgery. Regardless of disease symptoms, it is important to realize that these individuals reported feeling better after they became aware that they had coronary heart disease. The Improvement in lifestyle (decreased work, increased exercise and social activity, and decreased Type A behaviors) may be an important factor in determination of feelings of health status.

\section{Question 7}

Relationships between life satisfaction and the variables relating to health and activity were analyzed using correlational statistics. It was found in this study that significant relationships existed between life 
satisfaction and self-rated health ( $r \underline{s}=.65)$, social activity $(r \underline{s}=.65)$, and sexual enjoyment $(r \underline{s}=.38)$. Significant relationships also existed between the variables of self-rated health and social activity $(r \underline{s}=.57)$ and sexual enjoyment $(r \underline{s}=.34)$.

These findings were consistent with the Palmore and Liukart (1972) study which found that self-rated health was the predominant variable in an analysis of health and activity variables thought to influence life satisfaction. A subsequent study by Palmore and Kivett (1977), also found that self-rated health, social activity, and sexual enjoyment were significantly related to life satisfaction.

These findings support the idea that one's health is the most important factor in determining life satisfaction. If an individual feels healthy, then activities in his/her life will be perceived as satisfying.

\section{Question 8}

The relationships analyzed between activity balance satisfaction and activities of daily living found that no one variable of activities of daily living (work, leisure, or self/family care) individually impacted upon activity balance satisfaction. Although there were 
changes in the percent of time spent in these activities following hospitalization, they did not individually have an impact on determining activity balance satisfaction for the respondents of the current study.

The Mungai study (1984) found that activity balance satisfaction was directly correlated with the number of hours worked. This was not found in this study. Mungai studied a population of individuals who were typically regulariy working on an overtime basis, and extra free time may have provided them with a positive perspective on activity balance. The current study, however, was based on a population of respondents who typically were retired, or worked less than a typical 40 hour work week, and their cardiac rehabilitation program provided a built-in social activity, as well as exercise, to their leisure time. The combination of decreased work hours and increased leisure hours may have contributed to respondents' feelings of satisfaction with activity balance.

Question 9

When addressing the relationship between life satisfaction and activity balance satisfaction, no studies were found in the literature which addressed this relationship specifically. The importance of a balanced 


\begin{abstract}
lifestyle is an integral aspect in occupational therapy theory, and Mungai (1984) studied the importance of satisfaction with that balance in daily life. The findings in the current study indicated no positive relationship between respondents' feelings of life satisfaction and activity balance satisfaction, although relationships were evident between some variables related to activity balance (productive, social, and exercise time).
\end{abstract}

\title{
Discussion
}

The primary purpose for conducting this study was to determine whether quality of life and lifestyle changes occur among patients who have been hospitalized for MI or cardiac surgery and have participated in rehabilitation programs. The data analysis determined that these changes may be possible, and that individuals perceived that they could improve long-time habits, with some effort. This population reported that they were able to improve most risk factors, particularly diet, exercise levels, and relaxation techniques. With these reported changes, the participants found that life satisfaction actually improved. The participants in this study felt that they were healthier after hospitalization than before, and that this had a significant impact on life 
satisfaction. Self-rated health was found to be a major factor in previous studies of life satisfaction as well (Palmore \& Liukart, 1972). Palmore and Kivett (1977) found that life satisfaction was significantly related to the factors of self-rated health, social activity, and sexual enjoyment. The differences pre- and posthospitalization between these variables were also found to be significant variables in this study.

Work hours, as a factor, were not found to contribute to activity balance satisfaction. The Mungai (1984) study of activity balance among corporate employees found that the majority of one group of employees worked 48 minutes longer than a typical 8 hour day, and was generally unsatisfied with activity balance. The current study involved a group of individuals who worked less than the average 8 hour day and reported that they were generally more satisfied with activity balance. The statistical relationship between work and activity balance satisfaction was not found to be significant in this study, however.

Along with assessing life satisfaction, this study also involved looking at cardiac rehabilitation programs, as perceived by those participating in them. Browner (1987) emphasized the importance of assessing the impact of available rehabilitation programs for quality review. As apparently all risk factor skills had been taught in 
an educational format at the YMCA Cardiac Rehabilitation Program, from which subjects were drawn for this research, it was important to assess the degree to which individuals were able to integrate these skills into their lifestyles. It was found the subjects reported that strenuous exercise was increased in their daily activity balance, and productive hours decreased. Participation in the twice weekly exercise rehabilitation program may have affected their lifestyle. Responses from the open-ended portion of the questionnaire indicated that the rehabilitation program improved the quality of life, overall feelings of health, and increased social activity. Respondents indicated that they found diet difficult to change, though they were able to make changes to lower cholesterol levels and improve other parts of their diets.

\section{Conclusions}

Conclusions drawn from this study are: 1. There was reported improvement in life satisfaction among individuals who had been hospitalized for MI or cardiac surgery and who had participated in a cardiac rehabilitation program. Most participants were satisfied with their lives before hospitalization, and were even 
more satisfied afterward.

2. Individuals were reportedly more satisfied with activity balance after hospitalization.

3. Type A behavior characteristics were reportedly reduced after hospitalization, as were the feelings of time constraints.

4. Risk factors reportedly were changed through changing dietary habits, although it was perceived as a particularly difficult task.

5. A significant relationship was found between reported pre- and post-hospitalization differences in the variables of self-rated health and life satisfaction. 6. Participants felt significantly healthier after hospitalization and rehabilitation. The relationship between social activity hours and sexual enjoyment as they relate to life satisfaction was also significant.

\section{Implications for Occupational Therapy}

This study Identifies some of the factors related to the quality of life and life satisfaction of cardiac patients. These factors involved the participation of the Individual in varlous purposeful activities during their dally lives, including work, leisure, exercise, social activities, and managing adaptation to change in diet and activity balance. The participants in this 
study reported that they were able to change the balance and eypes of activities in their lives toward adaptation to accommodate for their disability, and in the process reported improvement in their levels of life satisfaction.

The literature provided various questionnaires which have been used to determine the relationship between various factors and life satisfaction (Walker \& McCoy, 1958, Neugarten, et al., 1961, Palmore \& Luikert, 1972). All questionnaires incorporated the purposeful activities of work, leisure and self/family care into the determination of life satisfaction. The philosophical base in occupational therapy includes the concept that "humans as active beings are influenced in their development by the use of purposeful activity or occupation... Human life is a process of continuous adaptation. Adaptation requires change in functions that promote survival and self-actualization" (American Occupational Therapy Association, 1979).

The results of this study showed that life satisfaction improved as work hours decreased, exercise was incorporated into the subjects' lives, and the self care activity of consuming a proper diet occurred, as did the overall improvement of health. These changes in activity types and amounts can be considered to be a change in activity balance. This study indicates that 
life satisfaction may be improved through changing activity balance and adding purposeful activities to one's life which are intrinsically and physically rewarding, which reinforces the viability and usefulness of occupational therapy.

The occupational performance perspective incorporates the importance of the roles of the activities of work, leisure and self care into the change from lack of function to function (Llorens, 1984). One of the central aims of occupational therapy is to help people achieve a maximum degree of wellness and sense of independence, with the inferred goal of improving life satisfaction (Decker \& Schultz, 1985). The therapist works toward this goal in various ways.

The therapist may help the individual with cardiac disease to adjust to various factors in life by providing a structured group exercise and education program to teach the management of cardiac risk factors, while at the same time providing emotional support in a sociable and relaxed environment. Counseling helps diminish the anxieties and fears of the patient and his/her family regarding the future and provides an excellent opportunity to educate the patient and family members on aspects of secondary prevention, such as controlling risk factors (Semmler \& Semmler, 1974). 
This study provides support for the theraplst and the patient that quality of life and feelings of health can improve desplte cardiac illness, which is an important fact to convey to patients who may be having difficulty adapting to their disability. As one of the most difficult risk factors to change, according to this sample group, is dietary habits, it would be helpful to incorporate low cholesterol/low fat recipes into the treatment plan, even on an inpatient basis. Increased social hours were found to be related to life satisfaction, which could be an indication for group treatment with this population, even on an inpatient basis. Ultimately, the individual patient provides the intrinsic motivation for success or fallure for his/her rehabilitation as participation and various life changes occur outside of the rehabilitation clinic walls. Matching a patient's needs with interests and abilities in an attempt to motivate the patient to adapt is one treatment method which may prove successful for this population (Burke, 1977).

From a program planning perspective, current rehabilitation programs, particularly outpatient programs, appear to be successful with respect to patient education of risk factor management and incorporating group exercise into cardiac patients' lifestyles. Occupational therapists have yet to become involved in 
the outpatient, longterm programs on a large scale, and very little research has been conducted about this population from an occupational therapy perspective. Occupational therapists have become involved with this rapidly growing patient population on an inpatient basis. However, as hospital stays are becoming increasingly shorter, there is very little time to provide sufficient information on lifestyle changes and risk factor management. The patients have very little time, and may have less motivation, to absorb this material while in the hospital immediately following this stressful life event. Outpatient programs, however, can be developed to incorporate teaching this information at the time in which patients are beginning to need to utilize it in the home setting. The current outpatient programs, which are for the most part administered by professionals other than occupational therapists, focus on the strenuous exercise management of the cardiac patients, and subsequently, studies about cardiac rehabilitation tend to focus on these aspects (Fletcher, 1982). It is important, however, to include psychological and social factors, as well as physical factors, in the rehabilitation for this population. This is especially important as it is the combination of physical, emotional and social factors, and not solely physical factors, which are shown to have a causative 
effect on cardiac heart disease (PhIlip, 1982 and MRFITRG, 1982). The self/family care, work, dietary and emotional risk factors need to be fully addressed, as well as exercise. Occupational therapists, with the occupational performance frame of reference, could more fully develop these programs. Programs should include education by registered dieticlans, stress management techniques, work evaluations, assessments of adaptation to the new lifestyle, as well as the exercise programs, all in a supportive group setting.

This study may benefit occupational therapy as a profession in identifying methods and levels of adaptation following cardiac illness. This sample group supported the theory that humans are continually adapting to change in their lifes, and that quality of life and Iife satisfaction can improve as this adaptation occurs. Occupational therapists are committed, as a profession, to habilitation and improving the quality of life through the encouragement of positive adaptation to these life changes (Llorens, 1984).

Occupational therapists can provide information, training and support to patients, but the participants in this study showed that they were motivated intrinsically to make the necessar'y changes independently and to ultimately improve the quality of their own lives (rehabilitation is voluntary and risle factor management 
skills must be practiced independently at home). Understanding the importance of motivational factors, whatever they may be on an individual basis, is vital to the perception of a positive quality of life for cardiac patients, and should thus be intrinsic to any rehabilitation program.

\section{Recommendations for Further Research}

This study examined the well being of cardiac rehabilitation patients from one rehabilitation program only. The following recommendations are made for further research in this area: 1) conduct longitudinal studies on activity balance and life satisfaction on a well population over several years; 2 ) study the development and success rates of a variety of types of cardiac rehabilitation programs; 3) examine life satisfaction and activity balance changes after cardiac illness over several years; and 4) conduct studies of the changes in type A behavior on a longitudinal basis among cardiac patients.

Summary

Life satisfaction and the balance of daily activity are important factors in the intrinsic motivation for 
lives of patients following hospitalization for cardiac illness. Cardiac heart disease is an ever-increasing problem in the United States, and as new methods are being developed for increasing lifespans, the cardiac heart disease patient population is growing rapidly. The purpose of this study was to identify changes in life satisfaction among patients who have undergone hospitalization for cardiac surgery or myocardial infarction.

A questionnaire was developed which asked about demographics, activity balance, Type A behaviors, life satisfaction variables and risk factor management before and after hospitalization for cardiac illness. The sample population consisted of voluntary participants who were involved in the Westside YMCA Cardiac Rehabilitation Program. The data from the questionnaires were collected and analyzed, using descriptive statistics and forinal correlational statistical tests.

The conclusions of the study are that for this population, which was mostly male, Caucasian, and highly educated, that they reported life satisfaction improved after hospitalization. Reported satisfaction with activity balance also improved, as did perceived health. It was found that this group reported working less hours, but was more involved in strenuous exercise and social time than previous to hospitalization. The participants 
reported that they were able to reduce type A behaviors, and improve risk management skills, though changing dietary habits proved to be difficult. They reported that they were generally more satisfied with their less stressful, less work-oriented, more social and healthier lifestyles which followed hospitalization for coronary heart disease and subsequent rehabilitation.

Implications of the study were discussed, which included improving occupational therapy for this population from various perspectives: evaluation and treatment of the individual patient, program planning and development, and enhancing the occupational therapy profession through continuing theoretical development. There is still a great deal of research to be conducted with respect to the cardiac patient and to enhancing Iffestyles anà improving life satisiaction for $a l l$ patient groups. Occupational therapists must continue to pursue the improvement of life satisfaction through the study of human adaptation and habilitation in order to advance quality care with individuals with cardiac disease. 
REFERENCES

Abbott. A. V., \& Vogel M. (1985). Letter to Editor:

Psychosocial influence on mortality after myocardial

infarction. New England Journal of Medicine, 312, (1), $50-51$

Adams, D. I. (1969). Analysis of a life satisfaction

index. Journal of Gerontology, 24, 420-474.

American Occupational Therapy Assoclation. (1972).

Occupational therapy: Its definition and function.

American Journal of Occupational Therapy, 26, 204.

American Occupational Therapy Association. (1979).

Philosophical base in occupational therapy. Official

Documents, Representative Assembly.

American Occupational Therapy Association. (1979). Role

of the occupational therapist in the promotion of

disabilities. American Journal of Occupational

Therapy, $33,50-51$.

Barborlak, J. J., Anderson, A. J., \& Rimm, A. A. (1983). Changes in avocational activities following coronary artery bypass surgery. Journal of Cardiac Rehabilitation, $\underline{3}, 214-216$.

Berger, B., Hopp, J. W., \& Raettig, V. (1975). Va.lues clarification and the cardiac patient. Health Education Monographs, $\underline{3}$ (2), 191-199. 
Browner, W. S. (1986). Estimating the impact of risk factor modification programs. American Journal of Epldemiology, 123 (1), 143-151.

Byrne, D. G. (1981). Type A behavior, life events and MI : Independent or related risk factors? British Journal of Medical Psychology, 54, 317-377. cintril, H. (1965). The Pattern of Human Concern. New Jersey: Rutgers University Press. Carleton, R. A., \& Lasater, T. M. (1983). Coronary heart disease and human behavior. Preventative Medicine, 12, 610-618.

Comoss, P. M., Burke, E. A. S., \& Swa11s, S. H. (1979). Cardiac Rehabilitation, a comprehensive nursing approach. Philadelphia: J.B. Lippincott Company. Decker, S. D., \& Schulz, R. (1985). Correlates of life satisfaction and depression in middle-aged and elderly spinal cord-injured persons. American Journal of Occupational Therapy, 39, 740-745. Eynew, T. R., \& Jones, J. M. (1984). Teaching psychosocial aspects of coronary care. The Journal of Family Practice, 18 (1), 107-113.

Erdman, R. A. M., \& Duivenvoorden, H. J. (1983). Psychologic evaluation of a cardiac rehabilitation program: A randomized clinical trial in patients with MI. Journal of Cardiac Rehabilitation, 3, 696-704. 
Fletcher, G. F. (1982). Results of cardiac rehabilitation programs in improving the functional state of patients. hest, 82, 801 .

Friedman, M.. \& Rosenman, R. H. (1971). Type a behavior pattern: Its association with coronary heart disease. Annals of Clinical Research, $3,300-312$. Friedman, M., Thorensen, C. E., Gill, J. J., Ulmer, D., Thompson, L., Powell, L., Price, V., Elek, S. R., Rabin, D. D., Braell, E., Levy, R. A., \& Tasto, D. L. (1982). Feasibility of altering Type A behavior pattern after myocardial infarction. Circulation, $\underline{66}(1), 83-92$.

Glueck, C. J. (1985). Role of risk factor management in progression and regression of coronary and femoral artery atherosclerosis. American Journal of Cardiology, 57, 35G-40G. Goldman, L., \& Cook, F. (1984). The decline in ischemic heart disease mortality rates. Annals of Internal Medicine, 101, 825-836. Gregory, M. (1983). Occupational behavior and life satisfaction among retirees. American Journal of Occupational Therapy, 37, 548-553. Gundle, M. J., Reeves, B. R., Tate, S., Raft, D., and Mclaurin, I. P. (1980). Psychosocial outcome after coronary artery surgery. American Journal of 
Hackett, T. P., \& Cassem, N. H. (1982). Coping with cardiac disease. Advanced Cardiology, 31, 212-217. Jenkins, C. D., Rosenman, R. H., \& Zyzanski, S. J. (1974). Prediction of clinical coronary heart disease by a test for the coronary-prone behavior pattern. The New England Journal of Medicine, 290(23), 1271-1275.

Johnston, D. W., Cook, D. G., \& Shaper, A. G. (1987). Type A behavior and ischemic heart disease in middle aged British men. British Medical Journal, 295, 86-88.

Kielhofner, G., \& Burke, J. (1980). Model of human occupation (Parts 1-4). American Journal of Occupational Therapy, 34, 572-788.

King, L. J. (1978). Science of adaptive responses. American Journal of Cccupational Therapy, 32 , 429-437.

Kornitzer, M. (1982). Primary coronary risk factors and secondary prevention of coronary heart disease. Advanced Cardiology, 31, 162-167.

Llorens, L. A. (1983). Changing balance: Environment and individual. American Journal of Occupational Therapy, 38, 29-34.

Lohmann, N. (1977). Correlations of life satisfaction, morale and adjustment measures. Journal of 
Gerontology, 32(1), 73-75.

McCoy, T. M. (1959). A study of life satisfaction of

the aged in protective environments. Unpublished

Master's Thesis, Giversity of Southern California,

Los Angeles, CA.

Metzner, H. L., Carman, W. J., \& House, J. (1983).

Health practices, risk factors and chronic diseases in

Tecumseh. Preventative Medicine, 12, 491-507.

Meyer, A. (1922). The philosophy of occupational

therapy. American Journal of Occupational Therapy, 1 , 1-10 .

Miller, P., Johnson, N. L., Garrett, M. J., Wickoff, R.,

\& McMahon, M. (1982). Health beliefs of and

adherence to medical regimen by patients with ischemic

heart disease. Heart and Lung, 11(4), 332-339.

Miller, P., Wikoff, R., McMahon, M., Garrett, M. J., \&

Johnson, N. (1982). Development of a health attitude scale. Nursing Research, 31 (3), 132-136.

Multiple Risk Factor Intervention Trial Research Group.

(MRFITRG). (1982). Multiple risk factor intervention

trial. Journal of American Medical Association,

$\underline{248}(12), 1465-1477$.

Mungai, A. (1984). The occupational therapist in

Industrial health promotion: A needs assessment for a corporate population. Unpublished Master's Thesis, San 
Jose State University, San Jose, CA.

Neugarten, B. L., Havighurst, R. J., \& Tobin, S.

(1961). The measurement of life satisfaction. Journal of Gerontology, $16,134-143$.

Palmore, E., \& Kivett, V. (1977). Change in life satisfaction: A longitudinal study of persons aged 46-70. Journal of Gerontology, 32 (3), 311-316. Palmore, E., \& Liukart, C. (1972). Health and social factors related to life satisfaction. Journal of Health and Social Behavior, 13, 68-80.

Pedretti, L. W. and Pasquinelli, S. (1990). Foundations for treatment of physical dysfunction. In L. W. Pedretti \& B. Zoltan (Eds.), Occupational Therapy Practice Skills for Physical Dysfunction. st. Louis: The C. V. Mosby Company.

Pelletier, K. (1975). Mind as healer, mind as slayer. New York: Delta Publishing Company.

Philip, A. E. (1982). Measuring the outcome of rehabilitation. Advanced Cardiology, 31, 232-236. Philip, A. E., Cay, E. I., Vetter, N. J., \& stuckey, N.A. (1979). Personal traits and the physical, psychiatric and social state of patients one year after myocardial infarction. International Journal of Rehabilitation Research, 2, 479-487.

Rahe, B. H., Scalzi, C., \& Shine, K. (1975). Teaching evaluation questionnaire for postmyocardial 
Infarction patients. Heart and Lung, 4 , 759-766. Reiff, G. G., Motoye, H. J., Remington, R. D., Napier, J. A., Metzner, H. I., \& Epstein, F. H. (1967). Assessment of physical activity by qustionnaire and interview. Journal of Sports Medicine and Physical Fitness, $\underline{7}, 135-142$.

Reilly, M. (1962). Occupational therapy can be one of the greatest ideas of 20 th century medicine. American Journal of Occupational Therapy, 16, 1-9.

Reilly, M. (1978). A response to: Defining occupational therapy: The meaning of therapy and the virtues of occupation. American Journal of Occupational Therapy, 32, 305-310.

Rimm, A. A., Hartz, A. J., Kalbfleisch, J. G., Anderson, A. J., \& Hoffman, R. G. (1980). Basic biostatistics in medicine and epidemiology. New York: Appleton-Century Crofts. Ross, J. K., Monroe, Diwell, A. E., Mackean, J. M., Marsh, J., \& Barker, D. J. P. (1981). The quality of life after cardiac surgery. British Medical Journal, $\underline{282}, 451-453$.

Ruberman, W., Weinblatt, A. B., Goldberg, J. D., \& Chaudhary, B. S. (1984). Psychosocial influences on mortality after myocardial infarction. New England Journal of Medicine, $311(9), 552-559$. 
Sabapathy, F. R. (1981). The organization and rehabilitation of the post-myocardial infarction patient. Singapore Medical Journal, 22(4), 236-238. Semmler, C., \& Semmler, M. (1974). Counseling the coronary patient. American Journal of Occupational Therapy, 28, 609-614.

Theorell, T., \& Rahe, R. H. (1972). Behavior and life satisfaction characteristics of Swedish subjects with MI. Journal of Chronic Diseases, 25, 139-147.

Tickle, L. (1980). A comparison of need satisfaction of older persons living in the community and in institutions. Unpublished Master's Thesis, University of Southern California, Los Angeles, CA.

Tornstam, L. (1975). Health and self-perception. The Gerontologist, 15, 264-270.

Vyden, J. K. (1983). Postmyocardial infarction management and rehabilitation. New York: Marcel Dekker, Inc. Westaby, S., Sapsford, R. N., \& Bentall, H. H. (1979). Return to work and quality of iife after surgery for coronary artery disease. British Medical Journal, 27, 1028-1031.

Wilkinson, L. (1986). SYSTAT: The system for statistics. Evanston, IL: SYSTAT, Inc. W1lson-Barnett, J. (1981). Assessment of recovery: With special reference to a study with post-operative 
cardiac patients. Journal of Advanced Nursing, $\underline{6}$, 435-445.

Winslow, E. B. J. (1982). Rehabilitation of the cardiac patient. Cardiac Rehabilitation Postgraduate Medicine, $\underline{71}(2), 114-127$.

Wood, V., Wylie, M. I., \& Sheafor, B. (1969). An analysis of a short self-report measure of life satisfaction: Correlation with rater judgements. Journal of Gerontology, 24(4), 465-469. Yersa, E. J., \& Baum, S. (1985, April). Relationship between engagement in daily occupations and life satisfaction among people with spinal cord injury. USC Occupational Therapy Research Colloquium, Los Angeles, CA. 
APPENDIX A

QUESTIONNAIRE COVER LETTER 
Dear Participant:

You have been selected to participate in a study of life satisfaction and daily activity balance among individuals who have undergone hospitalization and rehabilitation for heart attack or cardiac surgery. This study is being performed as part of the requirements for the Master's Degree in Occupational Therapy at San Jose State University.

Any information obtained in connection with this study will remain confidential. The completed research will be presented in my Haster's Thesis to the Occupational Therapy Department at San Jose State University. If you have any questions, or would like results of the study. you may call Lauri Michaels at (213) 453-2925.

PLEASE PITURN THE QUESTIONNAIRE IN THE ENVLLOPE PROVIDED TO SHARON RANDELS AT THE YMCA BY AUGUST 15, 1986.

Thank you very much for your assistance with my thesis research.

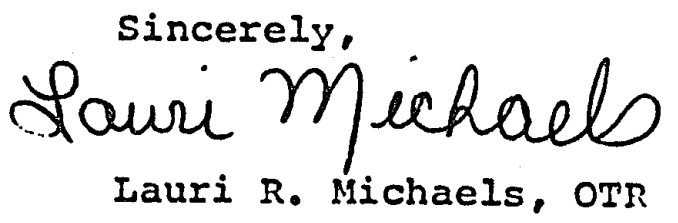


APPENDIX B

LIFE SATISFACTION QUESTIONNAIRE 
This questionneire hes been developed to aid in the research of coronary artery disease. Your cooperation to greatly appreciated. Ploses be obsured that your answers are confidential. There are no right or wrong answers; if you have any doubte about a specific question, pleses answer os best as you can. Pleaso enswer all questions. Thenk you for your time.

\section{A. HOSPITALIZATION/REHABILITATION INFORMATION}

1. For which of the following cardiac problews were you hospitalized? Check aore then one, if epplicable.
A. Myocardial Infarction [Heart Attack]
B. Bypass Surgery
C. Heort Volve Replacement
D. Other (please etate)

2. Whon woo the first time you ware hoopitelized for the above cardiac probleme?

$$
\text { Month/yaar }
$$

3. When wes your most recont hospitalizotion for the above cerdiac problame?

$$
\text { Month/Year }
$$

4. How many days were you hospitalizod during the most recent hospitalization for tho above cardiac probleme?

Days

5. Which of tho following 70 s the reason for your most racent hospitalizetion for cordiac probleas? Chock all that apply.
A. Myocerdial Inforction (Heart Attack)
B. Bypass eurgery
C. Heart Volve Replacement
D. Other

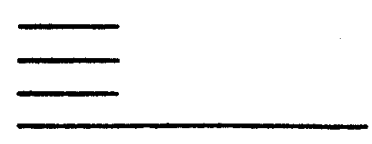


6. When did you begin your cordiac rahabilitation program?

Month/ Yeer

7. How often do you perticipate per week?

Times per meek

8. How long is each sersion?

Minutes

9. Have you been educated as to the following health practices os they rolate to cerdiac diseose through your cordiac rahobilitation program?

\begin{tabular}{|c|c|}
\hline $\begin{array}{l}\text { Diet } \\
\text { Smoking } \\
\text { Exercise } \\
\text { Relaxation } \\
\text { Alcohol Consumption }\end{array}$ & $\begin{array}{l}\text { YoB } \\
\text { Yos } \\
\text { Yos } \\
\text { YoB } \\
\text { Yos }\end{array}$ \\
\hline
\end{tabular}

10. Have you attended any other cardiac rahabilitation programs lincluding while hospitalized or as on outpationtl?

YeB___ No___

11. If yes to 10 , how long did you perticipate?

Weeks total

B. GENERAL INFORMATION

1. Sex:

Malo

Fomele

2. Age:

$16-29$

$30-39$

$40-49$

50-59

$60-69$

70-79

80 E above 
3. Raco:

Coucasion

Bleck

Asion American Lotin American Other

4. Marital Stotus:

Married

Divorced

Single

Widowed

Other

5. Highest Level of Educetion:

Legs than High School Degrea

High School Degreo

Voc./Prof. Dogres

Aseociates Degreo

Bachelors Degres

Graduate Degrea

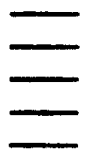

8. Famfly Incono Level:

$$
\begin{aligned}
& \text { Le8s than } \$ 10,000 \\
& \$ 10,000-29,000 / \text { year } \\
& 830,000-49,000 / \text { year } \\
& \$ 50,000 \text { and above/yoar }
\end{aligned}
$$

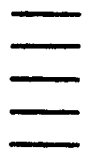

7. Employmant Status:
Employed pert-time
(Less than $30 \mathrm{hrs} /$ week)
Employed full time
Not employed
Potired
If employod, pleser state job titlo 


\section{MEDICAL INFORMATION}

The following questions refer to your first haspitalization for cardiac problems, as atated on page 1.

1. Do/did you suffer from sny of the following health problems?

In the yeer

Before Hospitalizetion:

Currently

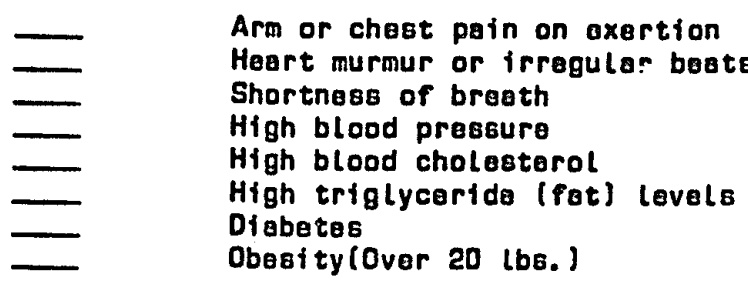

2. Smoking:

A. How many cigerettes, pipes, or cigers did/do you smoke?

In the year

Bofore Hospitalization

Currently

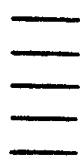

Never Enoked

0-10 cigaretteo, pipes or ctgaro per day

11-20 cigarettes, pipos or cigars per day

21-40 cigorettes, pipes or cigars par day

Over 40 clgarettes, pipes or cigars por day

B. How many years did you/have you smoked?

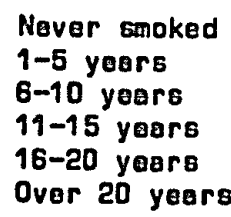

C. Do you sinoke currently:

Yos

No 


\section{FAMILY MEDICAL HISTORY}

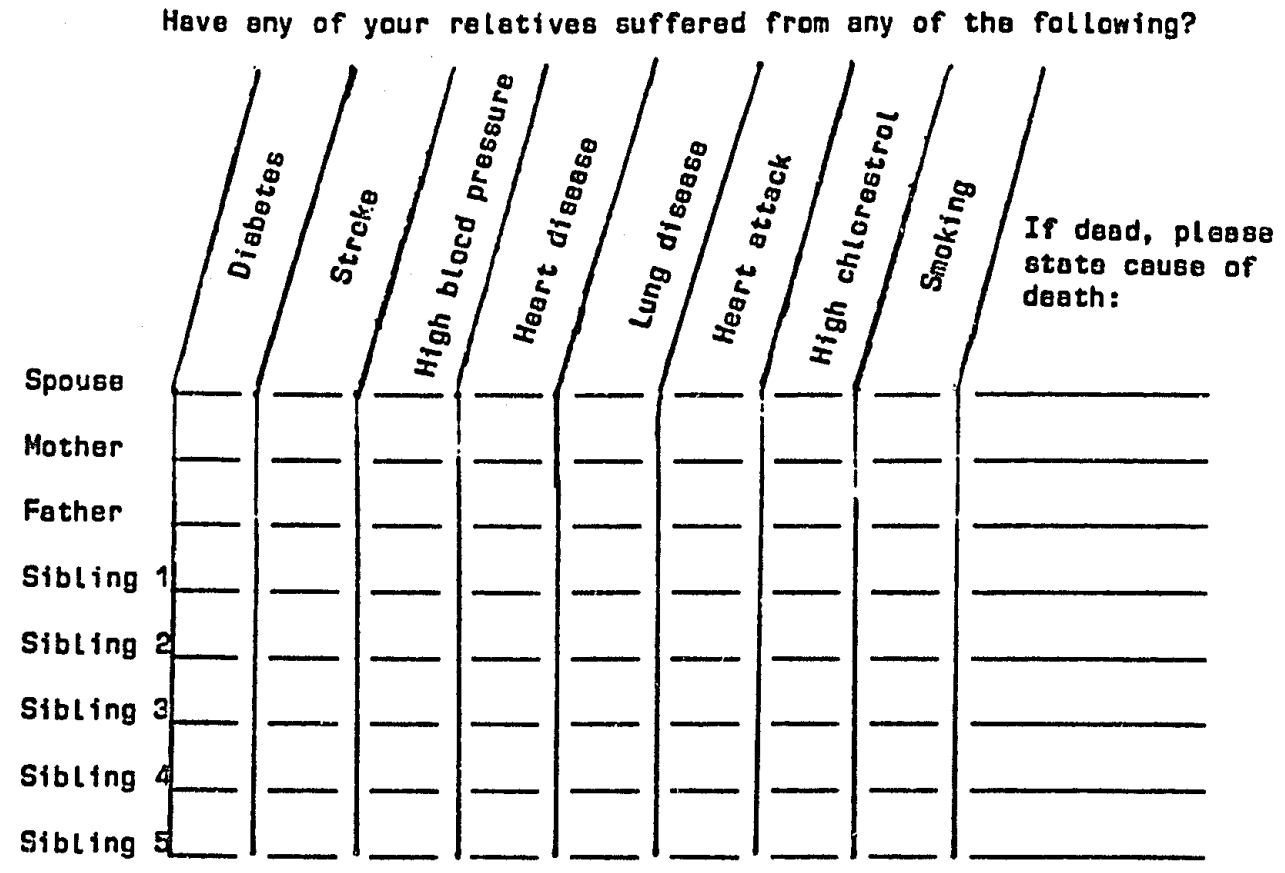

\section{F. DAILY ACTIVITY INFORMATION}

The information requestad below is besed on a typical 24 hour day (Monday-Fridey). Questions refer to six months before your first hospitalization for cardiac problems as mentioned on page 1 , and number of hours now.

1. How many hours in your day do you/did you typically engage in wark activitiee? Work includes taske such as paid jobs, and unpaid work such as housework or volunteer activities. This also includes commuting time, if applicable.

Hours $81 x$ months before hospltalization

Hours now

If no longer employed, please state last date of employment: 
2. How many hours in your day do you/did you pursue the following Leisure tasko?

A. Sedentary taske or strict rolaxation, such as roading, watching tolovision or ploying cards:

Hours six months before hospitalization

Houre now

B. Tesks requiring moderate exertion, such as gardening, walking, or social activities with friends:

Hours oix monthe before hospitelization

Hours now

C. Tosks requiring otrenuous exercise, buch os tennis, swimming or fest welke:

Hours six months before hospitalization

Hours now

3. How meny hours in your day do you/did you ongege in gelf or family-care tasks, such os dressing, house ropairs or washing dishes?

Hours six months before hospitelizetion

Hours now

4. How many hours in your day do you/did you geleap?

Hours six months before hospitalization

Hours now

5. How frequently have you taken a vocation during the last five yoars? Vacation connotes time off work for leisure; hospitalization is not included.

Heoks during the lost five years 
6. Do you feel satisfied with the belance of ectivities in you life?

$\begin{array}{ll}\text { Yes } & \text { Six months before hospitalization } \\ \text { No }_{\text {Yes }} & \text { Currently } \\ \text { No }^{\text {No }} & \end{array}$

\section{F. PERSONALITY INFORMATION}

1. Do/did you foel that you are often rushed, or that you have much to do and not enough time in which to do it?

$\begin{array}{lll}6 \text { montho before } & \\ \text { Hospitalizetion: } & \text { Currentiy } \\ - & \text { Sometimes } & - \\ - & \text { Always } & \\ - & \text { Never }\end{array}$

2. Chock the items which epply to your temporment. Ploses mark all items which epply to you.

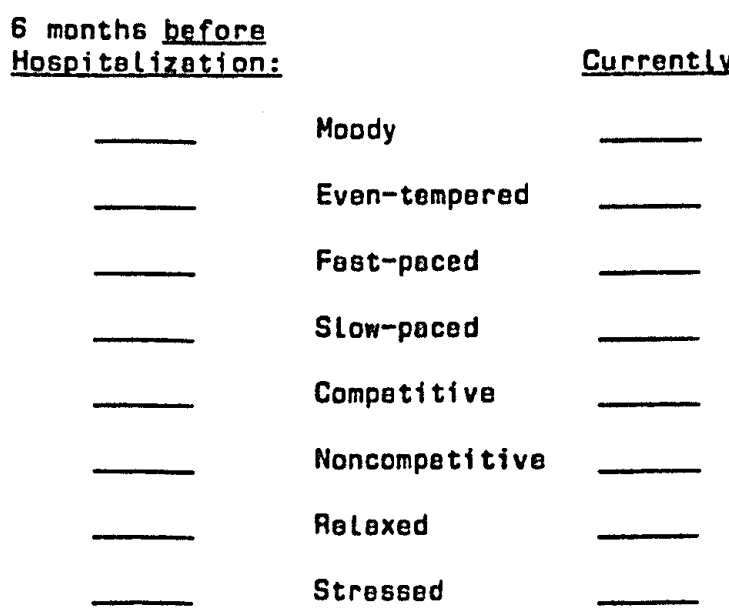


B

\section{G. LIFE SATISFACTION}

1. Self-roted heolth: an a scole of 0 to 9 , pleseo circle the number which best indiceted what you bel teve to be your level of heglthe

A. Six months before hospitalization:

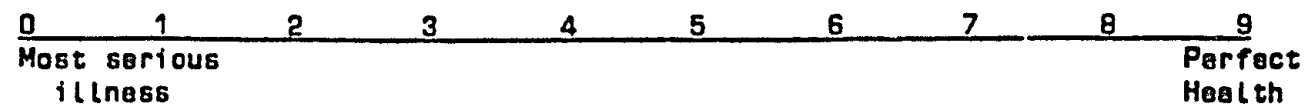

B. Currontly:

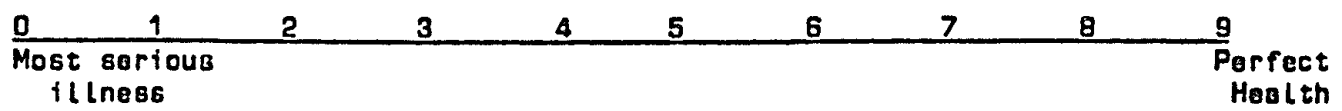

2. Orgenizotional octivity: Please indicete the number of religious gerytcos and maetings of other groups, such as clubs, unions or ossoctations you usually attend eoch month.

meetings monthly ofx monthe before hospitalization

meotings monthly ot present time

3. Sociel activity hours: Plesse etate the number of hours epent during a typical weok attending seciel activities, such os sports ovents, lectures, concerts, visiting friendo or rolatives, telephoning or writing, attending partios, oating out, or ontertoining. hours per wook six months bofore hospitalizetion hours per weak currently

4. Productive hours: Ploose state the number of hours spent during a typical week doing housework, volunteer work, working for pay, yard work, repelring, mending, or other such octivities. hours per weok six montha beforo hospitalizetion hours per weak currently 
5. Sexual enjoyment: How much pleasure or enjoyment do you/did you have during sex relettone? Please circle eppropriate anewsr.

Six months before hospitalization:

$\begin{aligned} & \text { Six months before hospitalization: } \\ & \text { None } \\ & \text { Mild }\end{aligned}$
$\begin{array}{lll}\text { Currently: } \\ \text { None }\end{array}$

6. Please state what you bollave to be your level of life ostisfaction. Circle appropriato number.

A. Six months before hospitalizetion:

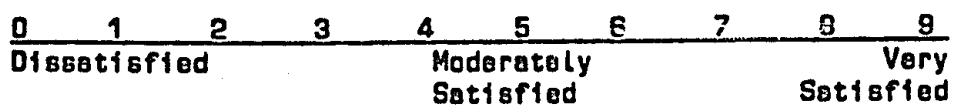

B. Currently:

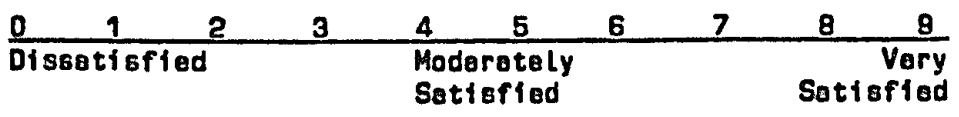

\section{H. RISK FACTOR MANAGEMENT}

1. This quastion refars to heolth prectices which you have been tought ot the rehobilitation program in order to prevont further cardiac problems. How do you foel you ore doing now, as compared with six months before hospitalization in the performances of these health proctices? BE HONESTI

$\begin{array}{lllll}\text { Diet } & & \text { Better } & \text { Same } & \text { Horse } \\ \text { Smoking } & \text { Non-Smoker } & \text { Better } & \text { Same } & \text { Worse } \\ \text { Exercise } & & \text { Better } & \text { Sama } & \text { Worse } \\ \text { Rolexetion } & & \text { Better } & \text { Same } & \text { Worse } \\ \text { Alcohol } & \text { Non-Drinker } & \text { Better } & \text { Same } & \text { Horse }\end{array}$

2. Please stote which orea of the above you would most like to change or improve

3. Please state which orea of the obove you found the most difficult to improve 
4. In the space below, please stato any othor ways in which the hospitalizetion or rahabilitation program has had an offect on your lifo-style or life setfsfaction. Plesse mention both good and negative offects or t8sues. 